OPEN ACCESS

Edited by:

Yuvaraj Hunge,

Daegu Gyeongbuk Institute of Science and Technology (DGIST), South Korea

Reviewed by:

Anuja Yadav,

Yeungnam University, South Korea Ananta Dhodamani,

Shivaji University, India

*Correspondence:

Khalid Umar

khalidumar4@gmail.com

khalidumar@usm.my

Specialty section: This article was submitted to Catalysis and Photocatalysis, a section of the journal

Frontiers in Chemistry

Received: 02 August 2021 Accepted: 09 September 2021 Published: 21 September 2021

Citation: Jamjoum HAA, Umar K, Adnan R, Razali MR and Mohamad Ibrahim MN

(2021) Synthesis, Characterization, and Photocatalytic Activities of Graphene Oxide/metal Oxides

Nanocomposites: A Review.

Front. Chem. 9:752276.

doi: 10.3389/fchem.2021.752276

\section{Synthesis, Characterization, and Photocatalytic Activities of Graphene Oxide/metal Oxides Nanocomposites: A Review}

\author{
Hayfa Alajilani Abraheem Jamjoum ${ }^{1,2}$, Khalid Umar ${ }^{1 *}$, Rohana Adnan ${ }^{1}$, Mohd. R. Razali ${ }^{1}$ and \\ Mohamad Nasir Mohamad Ibrahim ${ }^{1}$
}

${ }^{1}$ School of Chemical Sciences, Universiti Sains Malaysia, Pulau Pinang, Malaysia, ${ }^{2}$ Department of Chemistry, Faculty of Science, University of Sabratha, Sabratha, Libya

Sustainable water processing techniques have been extensively investigated and are capable of improving water quality. Among the techniques, photocatalytic technology has shown great potential in recent years as a low cost, environmentally friendly and sustainable technology. However, the major challenge in the industrial development of photocatalyst technology is to develop an ideal photocatalyst which must have high photocatalytic activity, a large specific surface area, harvest sunlight and shows recyclability. Keeping these views, the present review highlighted the synthesis approaches of graphene/metal oxide nanocomposite, characterization techniques and their prominent applications in photocatalysis. Various parameters such as photocatalyst loading, structure of photocatalyst, temperature, $\mathrm{pH}$, effect of oxidizing species and wavelength of light were addressed which could affect the rate of degradation. Moreover, the formation of intermediates during photo-oxidation of organic pollutants using these photocatalysts is also discussed. The analysis concluded with a synopsis of the importance of graphene-based materials in pollutant removal. Finally, a brief overview of the problems and future approaches in the field is also presented.

Keywords: graphene oxide, metal oxide, photocatalyst, zinc oxide nanocomposite, titanium oxide nanocomposite

\section{INTRODUCTION}

Clean and safe drinking water is essential for human health. Human health requires clean water, free of poisonous and carcinogenic compounds and dangerous microorganisms. Rapid industrialization and increase in the rate of population have been a matter of urgent need for authorities, and civil society all over the world. The United Nation (UN) Water Development Report 2020 estimates the lack of pure drinking water for over 748 million people and the water used by the manufacturing sectors would grow by a stunning $400 \%$ by 2050 (Ahmed and Haider, 2018; WWAP, 2018). Drinkable water is a key problem, particularly in regions that do not manage the eradication of toxic metal ions and industrial waste. As a result, a large number of harmful organic and inorganic compounds in the water bodies pose a major threat to human health (Escherichia et al., 2020). To address such kinds of issues there is a critical need to develop the wastewater treatment technique. Previously, major works were devoted to upgrading the natural aerobic techniques, coagulation, precipitation, diagnosis of membranes, photocatalysis, Fenton reactions, microbial fuel cells and adsorptions. Though, various restrictions-the difficulty of procedures and their time-consuming 
nature, increased operations costs and chemical agents utilized, aggregate loam generation and separation challenges were also hindered their prospective application (Raizada et al., 2020). In contrast to all of these constraints, advanced oxidation techniques are regarded to be among the best suitable methods for effective wastewater treatment based on photocatalytic heterogeneous and homogeneous oxidation of multiple organic contaminants. Photocatalytic reaction is a reaction that occurs under light and in the presence of a photocatalyst. This technology has several advantages, including protection of the environment, full pollutant degradation and no secondary pollution (Zhang et al., 2019). A wide range of potential photocatalysts restrict their use only with UV radiation and, thus, substantially increase their costs, particularly because solar light constitutes only $5 \% \mathrm{UV}$ radiation; therefore, need to provide a light energy by an external source (Moma and Baloyi, 2019; Umar et al., 2019). Several metal oxides have been examined as a heterogeneous photocatalyst for wastewater treatment (Yaqoob, Noor, et al., 2020). Few examples are iron (III) oxide, zinc oxide $(\mathrm{ZnO})$, niobium pentoxide, titanium oxide $\left(\mathrm{TiO}_{2}\right)$, tungsten trioxide, vanadium oxide and zirconia (Raizada et al., 2017).

Among all, $\mathrm{ZnO}$ and $\mathrm{TiO}_{2}$ are the most prominent material for their use as photocatalysts to treat the wastewater. $\mathrm{ZnO}$ has shown considerable potential in recent years due to its unique features such as its reasonable cost, strong oxidation capacity, extraordinary photosensitivity, bio consistency, acceptable photocatalytic performance, high chemical stability (Mullani et al., 2020), outstanding pyroelectric, and piezoelectric characteristics (Lee et al., 2016). Unlike the bulk materials, $\mathrm{ZnO}$ have a high definite surface area (i.e., very acute areas) which is having a critical responsibility in the generation of photogenerated charge carriers and reactive oxygen species (ROS) such as hydroxyl radicals which enable pollutant adsorption and mineralization when treated with UV light. Moreover, the comparatively wide bandgap (around $3.37 \mathrm{eV}$ ) requires UV radiation for the reaction to take place and the fast recombination and low resistance to corrosion prevent the practical application of electron-hole pairs. To date, $\mathrm{ZnO}$ performance has been improved using numerous strategies including metal loading, ion doping, connection with semiconductor, composite loading, and improved structural design etc (Dhodamani et al., 2020). The use of carbon based material to prepare visible light active photocatalysts or prolong the life of photo-generated electron-hole pairs is the most promising among the others. Although, $\mathrm{ZnO}$ has been combined with conventional carbon-based materials, graphene and its derivatives are one of the most promising options for this purpose (Chauhan et al., 2019). These materials show exceptional surface properties as well as outstanding electrical, thermal, chemical and adsorption characteristics. Graphene oxide (GO) is a good option for $\mathrm{ZnO}$-based integrating photocatalysts, due to the surface functionality of hydroxyl/carboxyl groups and its potential for charge separation properties (Gebreslassie et al., 2013; Umar et al., 2015; Serrà et al., 2019).

GO-based $\mathrm{ZnO}$ nanoparticles have recently become increasingly common in photocatalytic applications due to their superior physicochemical and photo-electrical characteristics. As the $p$ - conjugation structure displays great electronic mobility, the structural properties of GO-based nanocatalysts may increase the photocatalytic performance of $\mathrm{ZnO}$ considerably. The $\mathrm{GO} / \mathrm{ZnO}$ composite increases the separation of electron-hole pairs on the surface of $\mathrm{ZnO}$ and increases the harvesting the light energy ability in the visible region. In addition, they offer high efficiency because of the high specific surface, numerous active sites, and strong supporting properties (Haseen et al., 2020; Kumar et al., 2018; Yaqoob et al., 2020).

Similarly, $\mathrm{TiO}_{2}$ is also one of the most promising materials as a photocatalyst. Several investigations on the photocatalytic ability of $\mathrm{TiO}_{2}$ have been reported for different uses, including organic pollutants degradation and air cleaning etc. (Mir et al., 2012; Umar et al., 2012; Umar et al., 2016; Tobaldi et al., 2021). However, overall, the photocatalysts have some disadvantages such as cost-effectiveness, low efficiency, high recombination and requires $\mathrm{UV}$-radiation. $\mathrm{TiO}_{2}$ is widely utilized in wastewater treatment study as a photocatalyst due to its 1) excellent stability, 2) low price and low toxicity and 3) improved photocatalytic activity compared to other semiconductor materials (Mir et al., 2013; Umar et al., 2013; Malik et al., 2014; Bhanvase et al., 2017; Hunge et al., 2021). Therefore, photocatalytic activity is restricted to the visible Sun spectrum region. The rate of electron and hole recombination in $\mathrm{TiO}_{2}$ is also greater. The preparation of $\mathrm{TiO}_{2}$ composite-based photocatalysts with graphene derivatives is a way to resolve these issues. The electron mobility in case of graphene is greater, which improves the electron transportation and reduces the recombination of electron and hole. Moreover, the usage of graphene- $\mathrm{TiO}_{2}$ composite, $\mathrm{TiO}_{2}$ agglomeration may help prevent greater surface area and more active sites for pollutant degradation. It also increases the pollutant degradation rates by using a lower quantity of graphene- $\mathrm{TiO}_{2}$ composite photocatalyst. Graphene has high heat conductivity, improved load carrier's mobility and a superior mechanical strength (Yaqoob et al., 2021) and also a potential material for enhancing $\mathrm{TiO}_{2}$ photoactivities through these electrical and photonic capabilities (Dhodamani et al., 2020). The photoactivity of graphene- $\mathrm{TiO}_{2}$, as a result of higher visible light absorption and high affinity with other organic materials, is also improved (Jawaid et al., 2019). This review focuses on the characteristics, synthesis, and their important role in the photodegradation of $\mathrm{ZnO}$ and $\mathrm{TiO}_{2}-\mathrm{GO}$ nanocomposites. In this article, the characteristics of $\mathrm{ZnO}, \mathrm{TiO}_{2}$ and $\mathrm{GO}$, methodologies for $\mathrm{GO} /$ metal oxide nanocomposites synthesis, the photocatalytic mechanism for degradation, factors effecting the efficiencies of the photocatalyst, existing difficulties are discussed and recommendations for future works are proposed.

\section{Significance of Graphene Derivatives for Photocatalysis}

In general, graphite, diamond, and amorphous forms of carbon are classified, depending on the atomic structure and characteristics of carbon atoms. Graphene has 2D carbon with a nano-thick atomic sheet. The nanomaterials are directly 

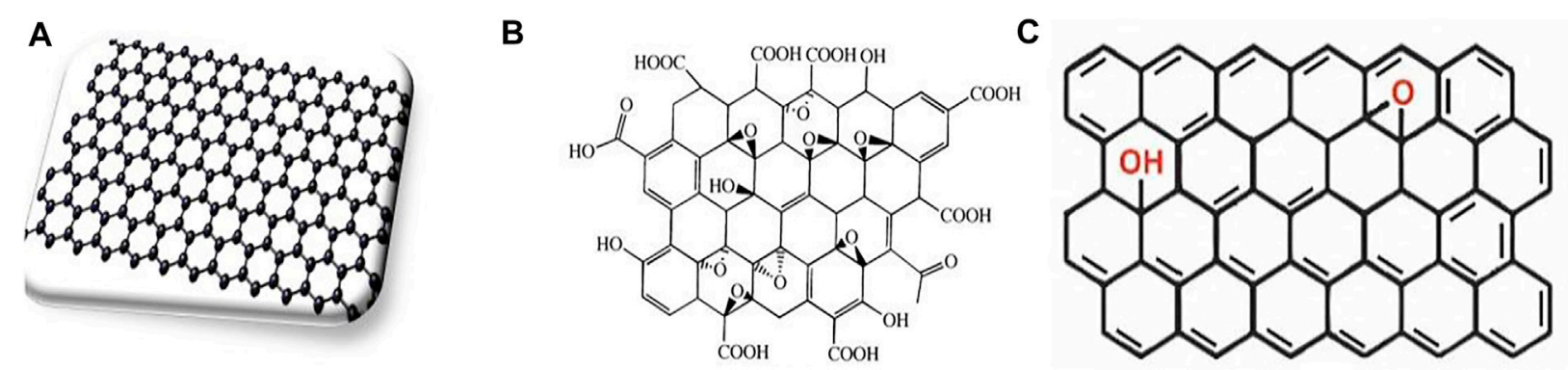

D

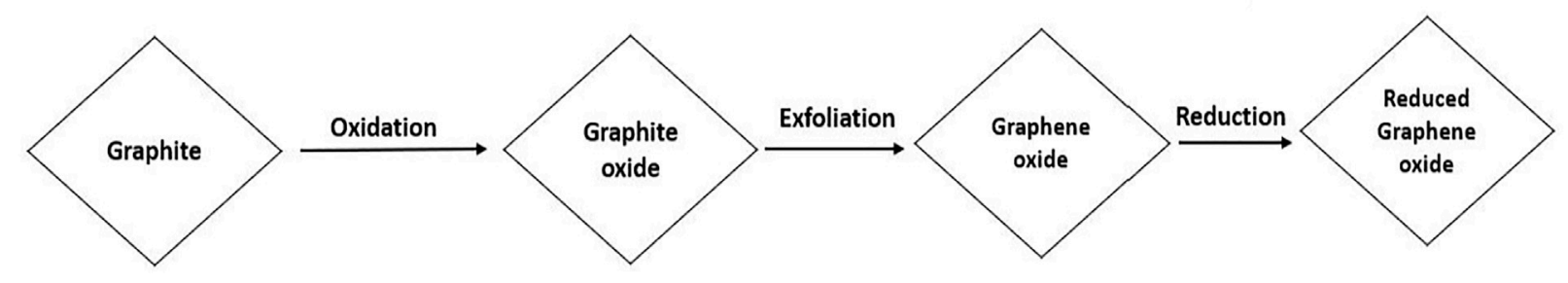

FIGURE 1 | Structure of (A) single layer graphene, (B) graphene oxide (GO) (C) reduced graphene oxide (rGO) and (D) the synthesis route of rGO through GO reduction (Adapted from Yaqoob et al. (2020) with MDPI permission).

concerned to such a unique substance since graphene is one of its fundamental constituents (Hussain et al., 2019). Graphene has also become a prominent material in a wide array of industries and applications, including energy conversion and storage beside its photocatalytic application (Ahmad et al., 2019; Dhodamani et al., 2019). As demonstrated in Figures 1A-D, graphene exists in many forms and they are generally used to manufacture heterogeneity in a range of applications. It also provide significant potential for generating redox vibrating media and water purification catalysts because of their vast surface and catalytic, optical, and electric characteristics (Shandilya et al., 2018). The very porous nature and widening surface of carbonbased nanoparticles also has strong adsorption characteristics, providing various active facilities for wastewater treatment (Singh et al., 2020).

GO is a relatively having extensive applications, formed by exfolation of graphite oxide. The first trial to synthesize GO was performed by Benjamin C. Brodie (1859), a chemist at Oxford University, and L. Staudenmaier in 1898 (Gao, 2012). Hummers et al. subsequently proceeded researching the substance using a potassium and nitric acid combination in graphite for the chemical reaction (Chen et al., 2015; Staudenmaier, 1898). Later, G. Offeman and Hummers tried, but with minor alterations, as seen in Figure 1D. Initially, $100 \mathrm{~g}$ graphite powder in sulfuric acid is combined with $50 \mathrm{~g}$ sodium nitrate. The mixture is then chilled on an ice bath to verify the presence of contaminants. Thirdly, in an agitated mixture of $300 \mathrm{~g}$ of potassium permanganate, graphite begins to oxidize, with a very thorough and tiny quantity of potassium permanganate to remain under $20^{\circ} \mathrm{C}$ in the suspension temperature. Fourth, with a tiny quantity of gas developed after 20 min of mixing, the combination suspension turns to a brownish-grey paste. Fifth, the mixture is supposed to be continuous for $30 \mathrm{~min}$ after which deionized water gently is added to the paste that generates a strong sparkling wave at $98^{\circ} \mathrm{C}$. Sixth, the diluted paste holds for 15 min when brown has turned. Seventhly, more deionized water is added to enhance dilution, adding $\mathrm{H}_{2} \mathrm{O}_{2}$ to remove manganese dioxide. The addition of peroxide leads to a vivid yellow suspension. Eighth, the overflowers are filtered in suspension, and the yellow-brown filter has to be rinsed two or three times. Ninth, the heated powder of the filtered goods is $40^{\circ} \mathrm{C}$. Finally, there is a single atomic sheet of GO (Ramachandran et al., 2015; Ortiz Balbuena et al., 2016).

Moreover, based on the surface functionalization in the development of graphene semi-continuous composites with tunable textural and surface chemical features, carboxylic, hydroxyl and epoxy groups combine with valuable functionality compounds such as polymeric materials and metal oxides and accountable to use in different applications (Vadivel et al., 2019). Furthermore, graphene-based nanocomposites thus offer an excellent field of study on water remediation and decontamination systems. Additionally, commercial graphene is very expensive to use as a photocatalyst, therefore the synthesis of graphene by using waste material via a hummer method could be the best option. Several efforts are ongoing on utilization of agro-waste material, biomass, paper etc. to prepare the GO, which can be further doped with metal oxide to use as a photocatalyst (Safian et al., 2020). This step can make the technique more reliable and cost effective.

\section{Graphene Oxide/metal Oxide Nanocomposite Synthesis Methods}

Due to their nano-size and good optoelectronic characteristics, the nanocomposites $\mathrm{GO} / \mathrm{ZnO}$ and $\mathrm{GO} / \mathrm{TiO}_{2}$ received considerable interest in the area of the photocatalysis. The lowering of recombination process and improved the 


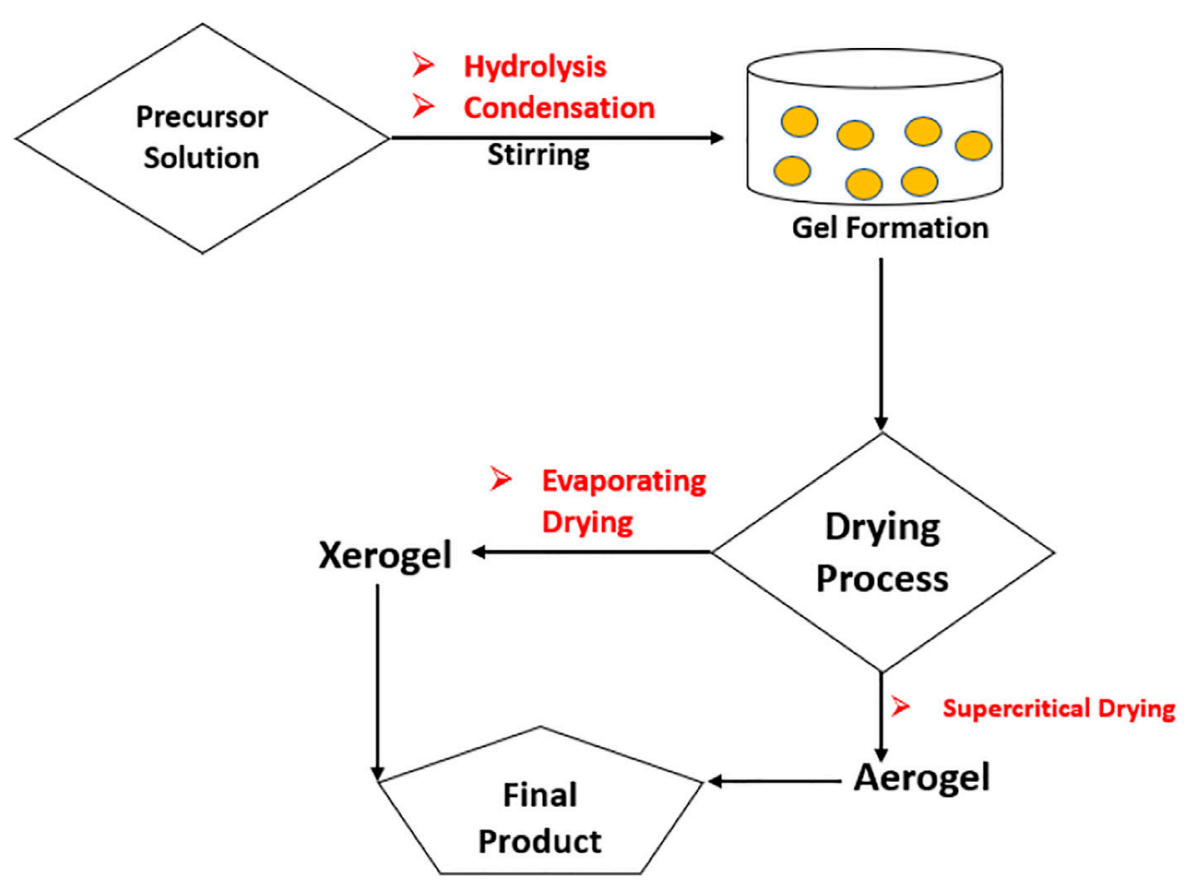

FIGURE 2 | Graphic presentation of sol-gel technique (Reproduced from Yaqoob et al., 2020 with MDPI permission).

resistance to photo-corrosion for the $\mathrm{ZnO}$ and $\mathrm{TiO}_{2}$ photo catalyst will be of great concern. The integration of $\mathrm{ZnO}$ and $\mathrm{TiO}_{2}$ nanoparticles into GO surface resulting in high stability and preventing graphene-based layers from being joined due to strong van der Waals pressures that exist among graphene-based layers. In material science, synthesis of new, more efficient nanocomposites based on graphene oxide/metal oxide is becoming more and more important and some regularly used techniques are listed as follows.

\section{Sol-Gel Method}

Sol-gel is one of the most promising approaches to produce composite, which was originally used in late 1980s, for the synthesis of nanocomposites. The sol-gel technique is a multistep procedure based on the metal precursors sequentially hydrolyzed for a metal hydroxide resolution followed by an instantaneous condensation to create a $3 \mathrm{D}$ gel, as illustrated in Figure 2.

The gel produced is dried, which leads to aerogel or xerogel and the desired product being formed afterwards. Aquatic or non-aquatic solvents are utilized, and results are more porous than other nanocomposites and have a larger area. Graphene materials are suitable precursors to the sol-gel approach because of their strong dispersive capacity to react with covalent aqueous or non-watery chemicals and functions. During the last several decades, $\mathrm{ZnO}$-rGO nanocomposites have been developed using sol-gel methods by including nanoparticles of $\mathrm{ZnO}$ on the surface of rGO sheets. One study reported by Azarang et al. on the preparation of $\mathrm{ZnO}$-rGO using sol-gel method to investigate the effect of rGO concentration on the optical properties of the nanocomposites. Figure 3 shows the TEM and HRTEM images of the nanocomposites at different rGO loading. The images reveal that the $\mathrm{ZnO}$ NPs are decorated and dispersed on the RGO sheets (Azarang et al., 2014). The major benefit of the sol-gel method is that the functional groups on rGO surfaces offer reactive and anchoring sites for the nucleation and growth of NPs. As a result, the metal oxide nanostructures will be chemically bonded to the GO/RGO surfaces.

\section{Solvothermal and Hydrothermal Method}

Solvothermal and hydrothermal methods played an important role in various scientific fields either for commercial research purposes or basic research. These approaches are favorable as the process is simple, efficient and low-cost. The methods are also environmental friendly as there are no hazardous organic solvents being used. Usually, water or ethanol was used as the solvent and the nanoparticles are formed under a high temperature and pressure for a given time. Using this one-pot method, the metal oxide can be attached and/or wrapped to the rGO sheets simultaneously with the reduction of graphene oxide (Alves et al., 2021). Last few years, these methods developed aggressively, especially in case of the augmentation of nanocrystalline. For a closed system, chemical reaction takes place between single or different precursors in solution like water at any greater temperature than their boiling point. The solvent investigated from its chemical and physical aspects which are dielectric constant, density, polarity, and also interaction between additives and reactants itself.

Marlinda et al. pursued the study of hydrothermal methods for the preparation of $\mathrm{ZnO} / \mathrm{rGO}$ composites. In basic procedure, graphene solution $(20 \mathrm{ml})$ was produced by Hummers' method and $\mathrm{Zn}(\mathrm{OH})_{2}$ solution $(2 \mathrm{ml})$ obtained from $\mathrm{Zn}\left(\mathrm{CH}_{3} \mathrm{COO}\right)_{2}$ 


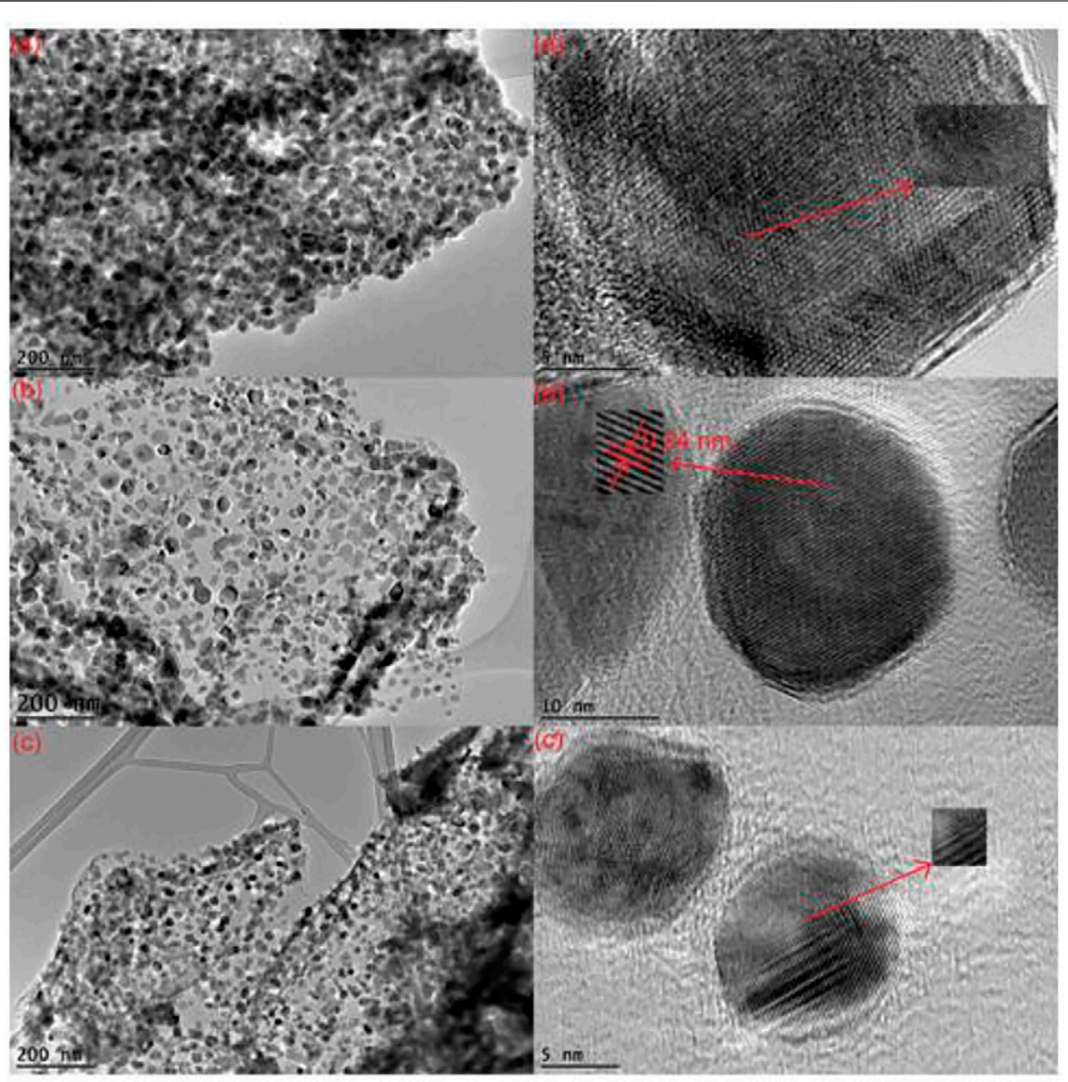

FIGURE 3 | TEM and HRTEM images of ZnO - rGO nanocomposites via sol-gel method at (A) low, (B) mid and (C) high rGO concentration (reproduced with permission from Azarang et al. (2014); copyright ${ }^{\circledR}$ 2020, AIP).

solution and $\mathrm{NaOH}(1 \mathrm{~g})$ was subjected to liquefaction in $25 \%$ $\mathrm{NH}_{3} \cdot \mathrm{H}_{2} \mathrm{O}(25 \mathrm{ml})$ respectively. The mixture was added slowly in presence of $\mathrm{NaOH}$ solution $(0.1 \mathrm{M})$ for increasing the $\mathrm{pH}$ until $\sim 10$ while the solution was kept stirred in an oil bath until dark brownish liquid produced at temperature $60 \pm 2^{\circ} \mathrm{C}$. Later, the mixture was being exposed into treatment involving hydrothermal methods for a day $(24 \mathrm{~h})$ at $180^{\circ} \mathrm{C}$ temperature. The generation of the end product was ended by washing it with ethanol, deionized water and lastly, dried up into an oven at $60^{\circ} \mathrm{C}$ temperature (Marlinda et al., 2012). Saravanakumar et al. prepared the $\mathrm{ZnO} /$ graphene nanocomposites through a modest temperature range in hydrothermal technique (Saravanakumar et al., 2013). The procedure started by $0.45 \mathrm{~g}$ of GO dissolved in $50 \mathrm{ml}$ of deionized water and put inside the sonicated bath for a period time of $30 \mathrm{~min}$ and $\mathrm{pH}$ solution tuned by adding $\mathrm{KOH}$ solution drop wisely. Next, $0.5 \mathrm{M}$ of zinc nitrate hexahydrate was added and stirred for about $15 \mathrm{~min}$. The $\mathrm{pH}$ increased using an ammonia solution that amplified alteration speed of $\mathrm{Zn}(\mathrm{OH})_{2}$ solution. After $30 \mathrm{~min}$ stirring, the solution was then transported to a glass container and wrapped definitely with a Teflon lid, and kept the container in the oven (hot air) for $10 \mathrm{~h}$ at distinct temperatures which are $98^{\circ} \mathrm{C}$ and $80^{\circ} \mathrm{C}$. The final product was then cooled until achieved $25^{\circ} \mathrm{C}$ temperature. The cooled sample was washed by using distilled water and ethanol. Ahmad et al. reported that the $\mathrm{ZnO} /$ graphene- $\mathrm{Ag}$ nanocomposites fabrication used simple solvothermal technique for organic dyes degradation (M. Ahmad et al., 2013). In previous procedure, $10 \mathrm{wt} \%$ of purified GO undergo liquefaction in ethylene glycol $(80 \mathrm{ml})$ through ultrasonication for $2 \mathrm{~h}$ was done and followed by centrifugation in order to get yellowish brown suspension. Different weight percent of silver acetate, $0 \mathrm{wt} \%, 2 \mathrm{wt} \%$ and $4 \mathrm{wt} \%$ together with $80 \mathrm{mg}$ of zinc acetate were liquefied in $80 \mathrm{ml}$ of ethylene glycol pursued with yellowish brown dispersion addition under continuous stirring (magnetic rod). Next, $20 \mathrm{mg}$ of $\mathrm{NaOH}$ was mixed into deionized water $(20 \mathrm{ml})$ and the solution then combined into a reaction mixture with magnetic stirred for $60 \mathrm{~min}$. The mixture will become homogeneous, and it was quickly transferred into stainless steel lined with a Teflon container. The mixture was then autoclaves for overnight $(24 \mathrm{~h})$ at $60^{\circ} \mathrm{C}$. Lastly, the prepared nanocomposites were washed and dried through the oven.

\section{Direct Growth of Metal Oxide Nanoparticles on the Surface of Graphene Oxide}

$\mathrm{ZnO}$ and $\mathrm{TiO}_{2} / \mathrm{GO}$ nanocomposite characteristically synthesized in optimized ratio. First, $\mathrm{Zn}^{2+}$ ions had been deposited evenly on the surface of $\mathrm{GO}$ and then turned it into $\mathrm{ZnO} N \mathrm{NP}$ with the addition of $\mathrm{NaOH}$ and $\mathrm{NaBH}_{4}$ at $150^{\circ} \mathrm{C} . \mathrm{ZnO} /$ graphene then produced at the end of reaction 


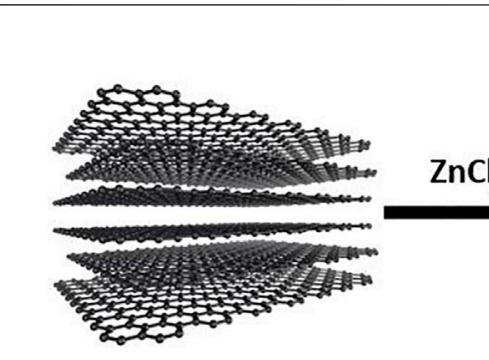

Graphene oxide layers

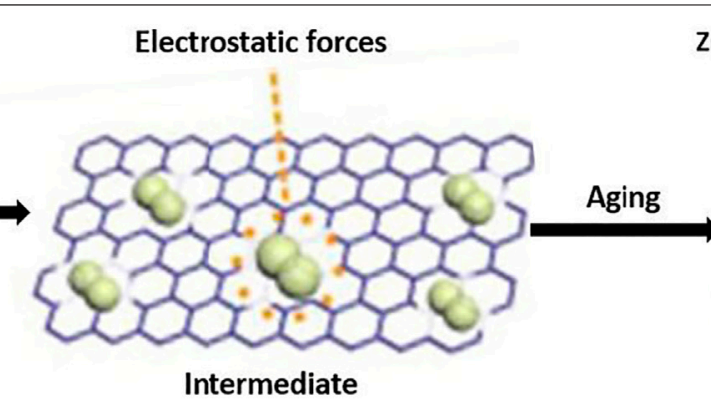

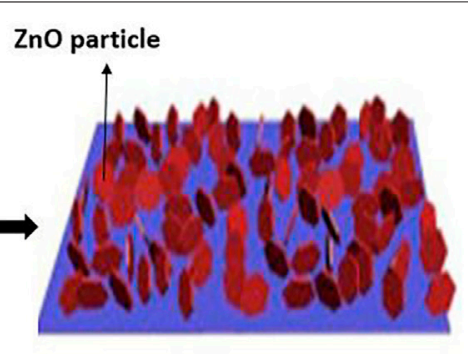

ZnO growth on $\mathrm{GO}$ sheet

FIGURE 4 | The ZnO nanoparticles growth on the surface of GO layers (Reproduced from Yaqoob et al. (2020) with MDPI permission).

after graphene oxide reduced into graphene. Generally, $\mathrm{ZnO}$ NPs have grown into a range, 10-20 nm size with distribution of exquisite particle physical size on the surface of graphene layers (Li and Cao, 2011). Chang et al. had reported the method for producing $\mathrm{ZnO} /$ graphene nanocomposite by using an easy insitu method (Chang et al., 2011). The procedure was started by mixing $\mathrm{ZnO}$ quantum dots into graphene in a fixed calculated ratio in order to earn a mixture of $\mathrm{ZnO}$ and graphene. Then, the mixture was cast with different substrates e.g., polyethylene terephthalate, quartz, glass and $\mathrm{SiO}_{2} / \mathrm{n}-\mathrm{Si}$ to generate $\mathrm{ZnO} /$ graphene thin films. Next, the films now were hardening by evaporating it at temperature $100^{\circ} \mathrm{C}$ and captivated inside zinc nitrate solution to in situ escalate $\mathrm{ZnO}$ quantum rods into $\mathrm{ZnO}$ nanorods where these nanorods used to make $\mathrm{ZnO}$ /graphene nanocomposites. These reactions aimed to enhance the substrate's adhesion. Lastly, nanocomposite was washed several times to remove the impurities from $\mathrm{ZnO}$ nanorods. Feng et al. reported in his research about exploration of new easy method to synthesis $\mathrm{ZnO}$ nanosphere/rGO nanocomposites through a hydrothermal supported in-situ gelatin method and also explained the $\mathrm{ZnO}$ dispersion effect on rGO (Feng et al., 2014). According to the conclusion, the $\mathrm{ZnO} / \mathrm{rGO}$ nanocomposite was prepared by using $\mathrm{Zn}(\mathrm{Ac})_{2} \cdot 2 \mathrm{H}_{2} \mathrm{O}$ and $\mathrm{GO}$ at different ratios, which they were distinctly added into the gelatin mixture. This reaction was done under mixing and stirring continuously at room temperature. At the same time, $\mathrm{NH}_{3} \cdot \mathrm{H}_{2} \mathrm{O}$ of $25 \mathrm{wt} \%$ were put drop wisely into mixture that was obtained before until the mixture achieved $\mathrm{pH} 9.0-10.0$ proceed by stirring with magnetic rod continuously for fixed $30 \mathrm{~min}$. After that, the obtained product was conveyed into Teflon lined $(25 \mathrm{ml})$ with stainless steel-based autoclaves for the same amount of time reaction as in $\mathrm{ZnO}$ synthesis. Last step, the end product obtained was washed with water, then dried out in vacuum at temperature $80^{\circ} \mathrm{C}$. RGO compounds had excellent electron transportation and improved well surface area that contributed good effects to improve the nanocomposite's photocatalytic reaction. Sahatiya and Badhulika also reported about an easy as one-step method for single graphene in-situ preparation which doped with zinc oxide (GO- $\mathrm{ZnO})$ nanocomposite through using electrospinning (Sahatiya and Badhulika, 2015). However, the general systematic proposed mechanism by in-situ growth of $\mathrm{ZnO}$ particles on the surface of graphene is present in Figure 4.

\section{Solution Mixing Method}

Solution mixing is a direct and efficient method that has been extensively used to prepare graphene/metal oxide composites. This method can be conducted at a low temperature. Besides, it promotes faster de-aggregation and dispersion of reinforcement material and produces composites with uniform structure. Prabu et al. prepared $\mathrm{ZnO}-\mathrm{rGO}$ composite by a direct solution mixing method. Initially, a spindle-shaped $\mathrm{ZnO}$ was prepared by hydrothermal method and the rGO was synthized using Hummer's method. From the study, they observed the spindle-shaped $\mathrm{ZnO}$ were found to be decorated on the partially reduced graphene oxide sheets (Prabhu et al., 2018). In another study they report a study on dumbbell-shape $\mathrm{ZnO}-\mathrm{rGO}$ nanocomposites. Similar to the previous study, the nanocomposites was prepared by a simple solution casting method. They used different concentration of rGO. In this study, a corresponding amount of rGO was dispersed in $25 \mathrm{ml}$ de-ionized water for $1 \mathrm{~h}$. Then, $100 \mathrm{mg}$ of the dumbbell-shape $\mathrm{ZnO}$ was added and continuously stirred for $12 \mathrm{~h}$. After that, the mixture was washed with ethanol and deionized water for several time. Finally, the $\mathrm{ZnO}-\mathrm{rGO}$ was dried overnight in an oven at $80^{\circ} \mathrm{C}$. The produced nanocomposites was used as a catalyst for the degradation of organic pollutant (Prabhu et al., 2019).

\section{Self-Assembly Method}

Self-assembly is an efficient process in to assemble micro or nanomaterials into some specific ordered structure or pattern. This was achieved by the interactions among the materials themselves. Previously, Du et al. fabricated $\mathrm{ZnO}-\mathrm{rGO}$ hybrid films via self-assembly method for use in supercapacitor application. In their study, they first synthesized $\mathrm{ZnO}$ nanoflakes and use it as a layers structure spacer. The hybrid film was achieved through ultrasonic mixing and subsequent selfassembly by vacuum-assisted filtration (Du et al., 2019). Another study was conducted to prepare a nanostructured graphene$\mathrm{TiO}_{2}$-porphyrin composite via surfactant-assisted self-assembly for degradation of Rhodamine $\mathrm{B}$. In their work, a graphene- $\mathrm{TiO}_{2}$ porphyrin hybrid material was synthesized by CTAB surfactant and graphene-assisted co-assembly of monomeric TCPP molecules with $\mathrm{TiO}_{2}$ nanoparticles. They composites with good integration of $\mathrm{TiO}_{2}$ particles (15-30 nm diameter) and aggregated porphyrin nanorods (50-60 nm width) and several 


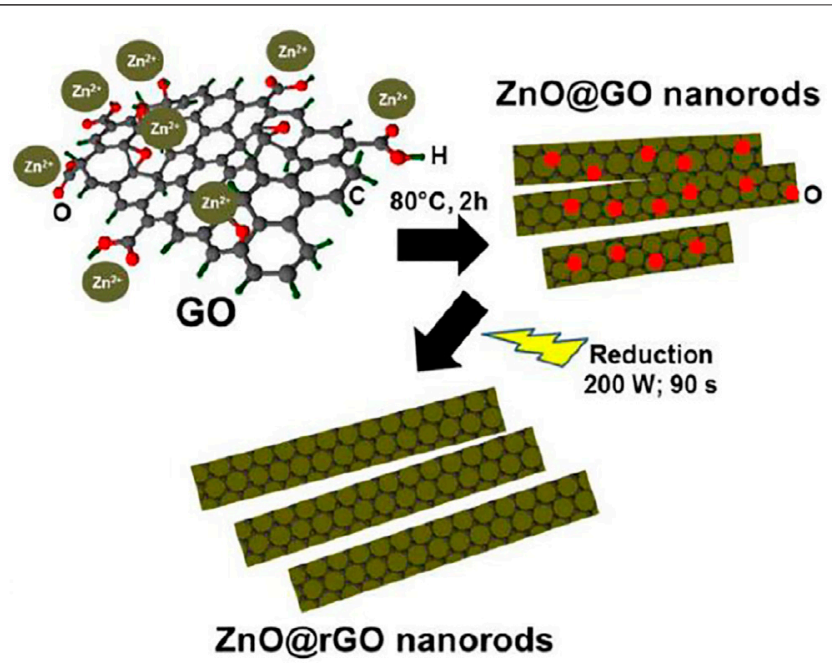

FIGURE 5 | Representation of the ZnO@rGO NR hybrids synthesis via microwave-assisted method. (Reproduced from Jana and Gregory (2020) with WILEY permission).

hundreds of nanometers in length on the graphene surface ( $\mathrm{La}$ et al., 2017).

\section{Microwave Irradiation}

Microwave irradiation is a rapid method that provides energy for chemical reaction. It generates rapid intense heating in the sample interior and thus reduces reaction times. In one study, rGO incorporated MOF-derived $\mathrm{ZnO}$ composites were prepared via the microwave-assisted method assisted reduction of GO in MOF-derived $\mathrm{ZnO}$ suspensions. In brief, $16 \mathrm{mg}$ MOF-derived $\mathrm{ZnO}$ was added into $20 \mathrm{ml} \mathrm{GO}$ solution. The solution was put into a focused microwave system and treated at $150^{\circ} \mathrm{C}$ with microwave irradiation power of $150 \mathrm{~W}$ for $10 \mathrm{~min}$. From this study, they obtained a good combination between $\mathrm{ZnO}$ and $\mathrm{RGO}$ as the surface of curled RGO nanosheets is packed densely by $\mathrm{ZnO}$ particles. The resulting composites were used as photocatalysts for the photocatalytic degradation of methylene blue (Zhu et al., 2017). Jana and Gregory synthesized ZnO-rGO core-shell nanorod hybrids using a microwave-assisted system. The representation of the synthesis is shown in Figure 5. In the first part, partial reduction was attained by chemical reduction under alkaline condition. $\mathrm{ZnO}$ was added into a round bottom flask containing $\mathrm{NaOH}$ and ethanol. Then, ethanolic solution containing GO was added after the mixture was stirred for $15 \mathrm{~min}$. Next, the solution was refluxed for $2 \mathrm{~h}$ at $80^{\circ} \mathrm{C}$. The suspension was centrifuged and the solid was washed with ethanol and deionized water before drying in oven at $40^{\circ} \mathrm{C}$ overnight. Finally, the dried powder was irradiated at $200 \mathrm{~W}$ in a reactor under vacuum for $90 \mathrm{~s}$ (Jana and Gregory, 2020).

\section{Ball Milling Method}

Ball milling is another interesting approached to prepare graphene/ metal oxide composites. This method is known to be environmentally friendly, cost effective and scalable method to produce the composites. During the ball milling process, a powder mixture is placed in a concealed container and undergoes high energy collision from the balls that create localized high pressure. This can be used to produce graphene from the graphite ruptured and can be further mixed with other metal oxide. Yin et al. prepared CIPs/ZnO/Graphene ternary lamelliform hybrid using ball milling method for using as a candidate in the absorption of low frequency microwave. The set up was consist of a ball milling tank $(500 \mathrm{ml})$ and grinding balls made up of stainless steel $(5 \mathrm{~mm})$. They fixed the ration of grinding balls to samples at 20:1 at which the mass of the balls is $500 \mathrm{~g}$ and the materials are $25 \mathrm{~g}$. Ethanol was used as dispersant in the process. The materials were milled under the rotate speed of $500 \mathrm{rad} / \mathrm{min}$ for $12 \mathrm{~h}$, and then the final product was separated from the grinding balls and dried under $60^{\circ} \mathrm{C}$ for $6 \mathrm{~h}$. The hybrid composites showed an excellent absorption performance due to the external planar anisotropy with flake shape after ball milled (Yin et al., 2019). Additionally, study on $\mathrm{ZnO}$-graphene nanocomposites was conducted by Lonkar et al. They used ball milling method and solution-based hydrothermal method. They found out that the ball milling method produced higher surface area and smaller $\mathrm{ZnO}$ particle size compare to the other method. Moreover, this study also reported that the composites from ball milling method have a superior photocatalytic activity than the composites form hydrothermal method (Lonkar et al., 2019).

\section{CHARACTERIZATION TECHNIQUES}

Composites preparation of $\mathrm{GO} /$ metal oxide is often characterized by several parameters like surface properties, optical activity, size, crystallinity, heat stability, shape, etc. These characteristics are the important informations that is required to develop composites with excellent properties. Herein, the characterization techniques are divided into following types; spectroscopic, microscopic and elemental analysis including crystalline phases analysis using XRD technique. Other characterization on thermal and physical properties of the composites will also be included in the discussion.

\section{Spectroscopic Analysis}

Fourier transform spectroscopy (FTIR) is widely used techniques to identify organic compounds and in some cases, inorganic compounds. It is a rapid and non-destructive method that could detect a range of functional groups and is sensitive to changes in molecular structure. FTIR measures the absorption of infrared radiation by the sample material against wavelength. From there, the infrared absorption bands identify molecular components and structures. This method is well fitted with regard to surface chemicals, surface chemical residues, and identification on the surface of NPs for organic functional groups (e.g., ketones, amines, etc.). In the case of GO/metal oxide composites, FTIR is best fitted with Raman spectroscopy to get the full view of the composites properties.

Another important technique that is commonly employed for GO-metal oxide nanocomposites is ultra-violent spectroscopy (UV-vis). UV-vis measure the amount of UV light absorbs by a substance. It can be used to determine analyte concentrations or 
A

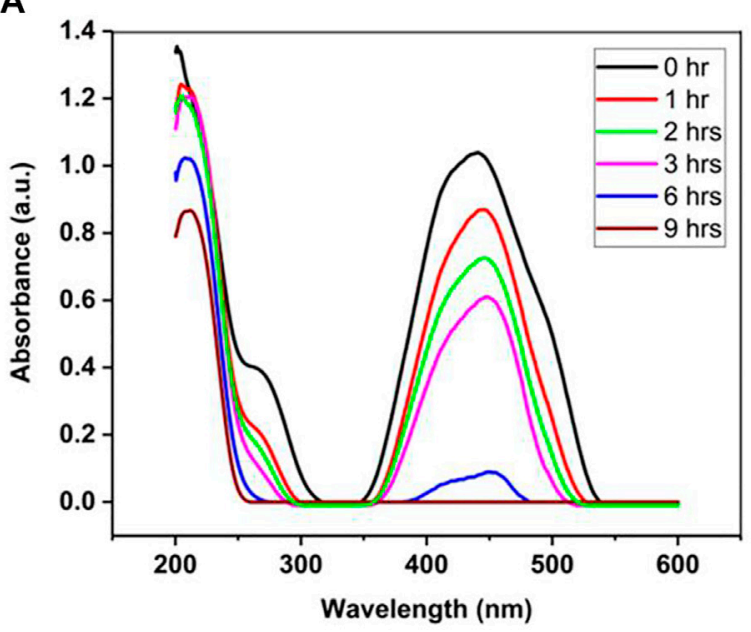

C

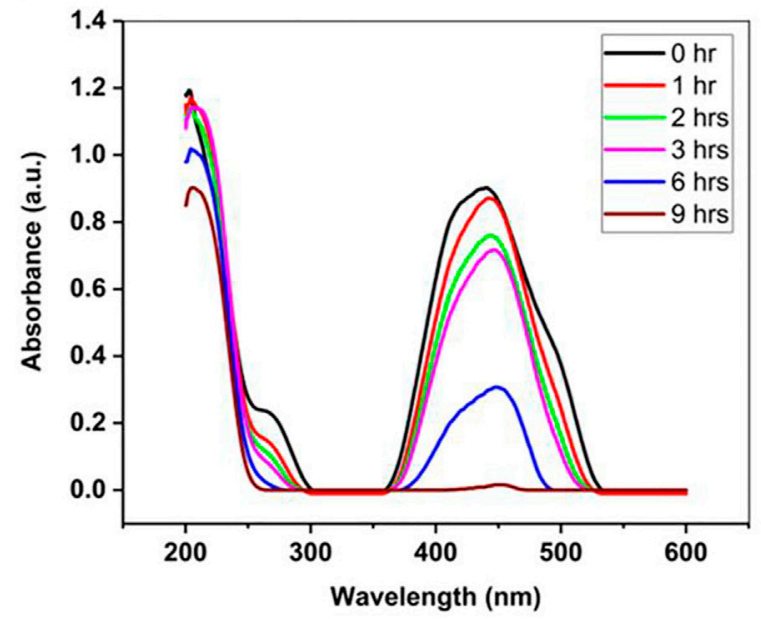

B

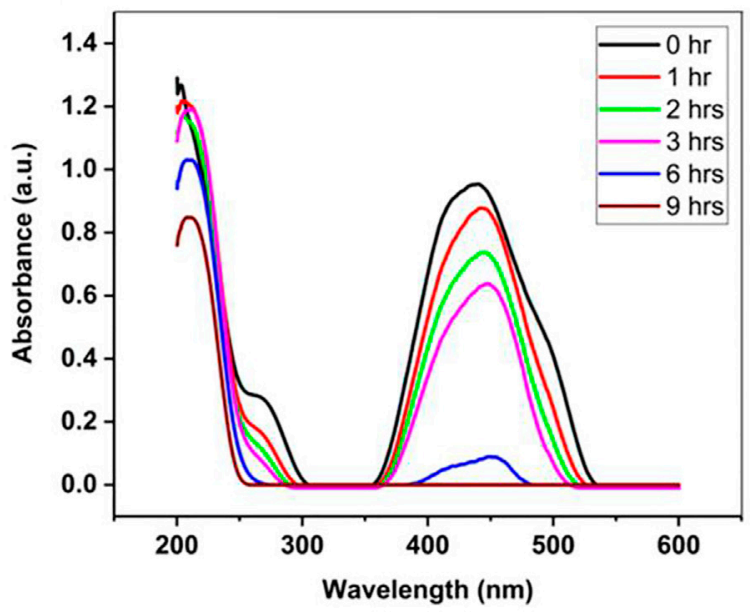

D

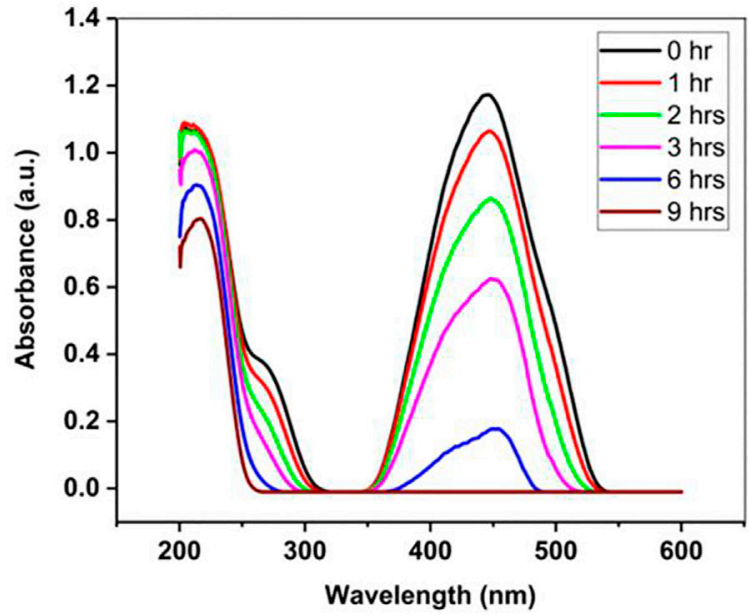

FIGURE 6 | Photocatalytic activity of ZnO-GO nanocomposites at (A) 1:10 (B) 1:15 (C) MDPI permission.

the chemical conversion of a component. The range of reflection and absorption is measured so that the nanocomposites visible and ultraviolet optical activity is defined (Aslam et al., 2021). The characteristics of various metal nanoparticles ranging from 2 to $10 \mathrm{~nm}$ could be based on light wavelengths of between 300 and $800 \mathrm{~nm}$. Similarly, the bandgap of the synthesized material via UV-Vis's spectroscopy was calculated by Eq. 1 .

$$
E_{g}=\frac{h c}{\lambda}
$$

Where, $\mathrm{c}=$ velocity of light $\left(3 \times 10^{8} \mathrm{~ms}^{-1}\right) ; \mathrm{h}=$ Planck's constant i.e. $6.626 \times 10^{-34} \mathrm{~J} \mathrm{~s} ; 1 \mathrm{eV}=1.6 \times 10^{-19} \mathrm{~J}$ and $\lambda=$ wavelength (Chauhan et al., 2019). UV-vis can be used to study the photocatalytic study of a catalyst as demonstrated by Ahmed and Haider. They synthesized $\mathrm{ZnO}-\mathrm{GO}$ at four different weight ratios for waste water treatment. From Figure 6, it can be observed that all the samples reached a complete degradation after $9 \mathrm{~h}$ irradiation time and the $\mathrm{ZnO}-\mathrm{GO}$ ratio did not have a significant effect on the photocatalytic performance as they degrade at the same rate (Ahmed and Haider, 2021).

In another study by Ruidíaz-Martinez et al., they used UV-vis technique, to study the electronic structure of the $\mathrm{rGO}-\mathrm{TiO}_{2}$ composite. The electronic properties were analyzed based on the diffuse reflectance spectra that are used to calculate the band gap energy. The calculation is done according to Kubelka-Munk transformed function as follow:

$$
(F(R) \times h V)^{\frac{1}{2}}=C\left(h V-E_{g}\right)
$$

where $\mathrm{n}$ is the constant for the type of optical transition, with values of $n=2$ for permitted indirect transitions, $n=3$ for forbidden indirect transitions, $n=1 / 2$ for permitted direct transitions, and $n=3 / 2$ for forbidden direct transitions. Figure 7 shows plots of the transformed Kubelka-Munk function against the energy of light. The results show that 


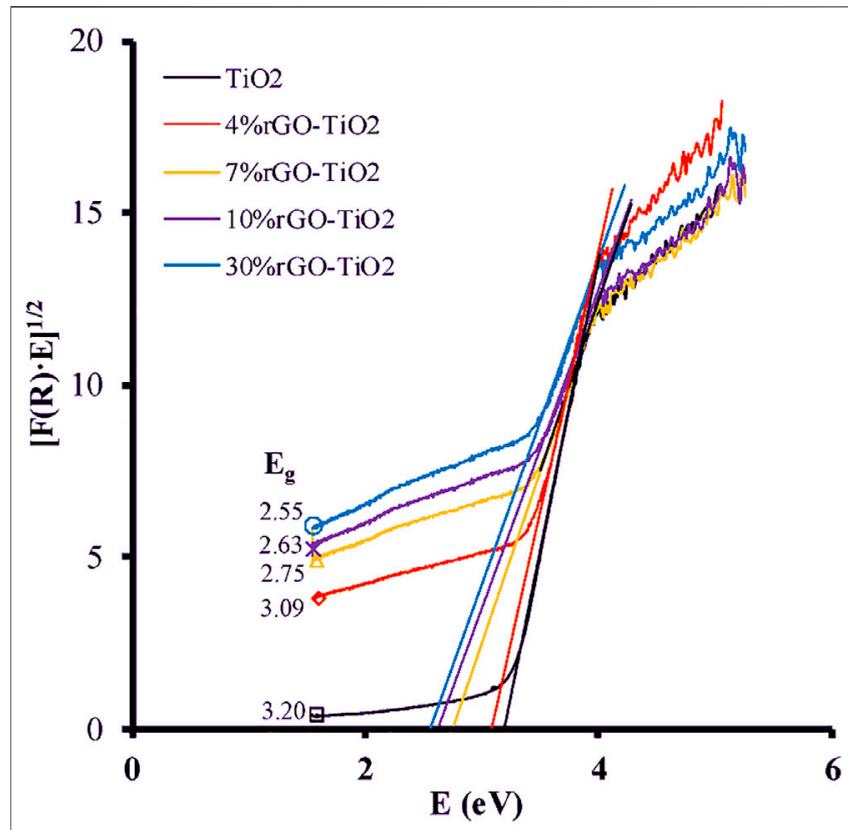

FIGURE 7 |Plots of Kubelka-Munk function and light energy for $\mathrm{TiO}_{2}$ and rGO-TiO 2 composites. Reproduced from Ruidíaz-Martínez et al. (2020) with MDPI permission.

increase amount of GO narrows the band gap energy in composites (Ruidíaz-Martínez et al., 2020).

\section{MICROSCOPIC ANALYSIS}

There are several types of microscopic analysis that frequently used for composites study including scanning electron microscopy (SEM), transmission electron microscopy (TEM). SEM is a technique that may be used to improve the sample's resolution. The surface morphology, such as determining the exact shape of nanoparticles and topographic analysis, is frequently studied using SEM and TEM methods. The main distinction is that TEM delivers more information about the interior structure and has higher resolution than SEM. The average size of material is also determined using such procedures or approaches. Meanwhile, the AFM method is often employed to collect information on the surface nature, size, shape, topography, roughness, and particle size distribution of nanocomposites (Nabi et al., 2020). The SEM images of $\mathrm{ZnO}$ and $\mathrm{ZnO}-\mathrm{GO}$ at different $\mathrm{GO}$ concentration are depicted in Figure 8. It can be seen that, the $\mathrm{ZnO}$ structure made up of rod and spherical-like particles. In comparison, the $\mathrm{ZnO}-\mathrm{GO}$ composites show more aggregated structures than the pure $\mathrm{ZnO}$. From Figures 8C-F, there are no present of GO sheets uncoated with $\mathrm{ZnO}$, indicating a good assembly between $\mathrm{ZnO}$ and $\mathrm{GO}$ phases for all the composites prepared (Mirikaram et al., 2021).

\section{Elemental Analysis}

Elemental analysis can be performed using energy dispersive analysis of X-ray (EDX), X-ray photoelectron spectroscopy
(XPS) and X-ray diffraction (XRD). XRD is used to examine nanocomposites' crystalline phase and is distinguished by diffraction patterns for a crystal structure. X-rays may penetrate nanoparticles in order to generate the particular pattern of diffraction (Wang et al., 2015). In addition, Debye-Scherrer formula and Bragg Law Equations have been utilized to compute the mean crystallite size and d-spacing of the produced material by means of XRD examination using Eqs. 3, 4 as shown below;

$$
\begin{gathered}
D=\frac{K \lambda}{\beta \operatorname{Cos} \theta} \\
d=\frac{\lambda}{2 \operatorname{Sin} \theta}
\end{gathered}
$$

where, $K=$ Scherrer constant, $B=$ full width at half-maximum (FWHM), $\lambda=$ wavelength of the X-ray, $\mathrm{D}=$ particle size and $\theta=$ Bragg angle while in Bragg's Law $d$ is the d-spacing. Besides that, EDX method may be used to determine the types of elements present in a sample as well as their concentration. It is also commonly used to estimate the elemental makeup of composites. Moving forward, XPS is a surface-sensitive quantifiable spectroscopic technique which relies on the photoelectric consequence that can detect the elements present in a material (elemental composition) or on its surface, as well as their chemical states, and the overall electronic structure and density of the electronic states in the material. Figure 9 displays the XPS spectra of $\mathrm{TiO}_{2}, \mathrm{GO}$ and $\mathrm{TiO}_{2}-\mathrm{GO}$ composites. The $\mathrm{TiO}_{2}$ and $\mathrm{TiO}_{2}-\mathrm{GO}$ show two peaks at the binding energies of 458.5 and $464.3 \mathrm{eV}$ for $\mathrm{Ti} 2 \mathrm{p}$, which was assigned to the $\mathrm{Ti} 2 \mathrm{p}_{1 / 2}$ and $\mathrm{Ti} 2 \mathrm{p}_{3 / 2}$. The spectrum of $\mathrm{TiO}_{2}$ demonstrated two peaks of $\mathrm{O} 1 \mathrm{~s}$ at 529.2 and $532.3 \mathrm{eV}$. The peaks of $\mathrm{O} 1 \mathrm{~s}$ at about 530.3 and $531.7 \mathrm{eV}$ were from the signal of $\mathrm{O}-\mathrm{H}, \mathrm{C}=\mathrm{O}$ and $\mathrm{C}-\mathrm{O}$ of $\mathrm{GO}$. The $\mathrm{TiO}_{2}$ revealed four peaks at the binding energy of 529.2, 530.8, 532, and $533 \mathrm{eV}$, respectively, corresponding to the oxygen atoms of $\mathrm{TiO}_{2}$ and $\mathrm{GO}$ (Shi et al., 2021).

\section{Others}

Thermal analysis of composites can be conducted through various instrumentation methods. Among all, thermogravimetric-differential thermal analysis (TG/DTA) is the most reported approaches used to illustrate the material's thermal stability and thermal potency. Other than that, particle size analysis (PSA) is a method for determining the average size of nanocomposites. Meanwhile, Brunauer-Emmett-Teller (BET) analysis is also can be employed to study the specific surface area and porosity of composites.

\section{GRAPHENE OXIDE/METAL OXIDE NANOCOMPOSITES AS PHOTOCATALYST}

A number of researches were published recently concerning the use as photocatalysts of graphene/metal oxide nanocomposites for their outstanding qualities in water purification. These nanocomposites offer several advantages for example, increased conductivity, adjustable property, optical behavior, durability stability and 


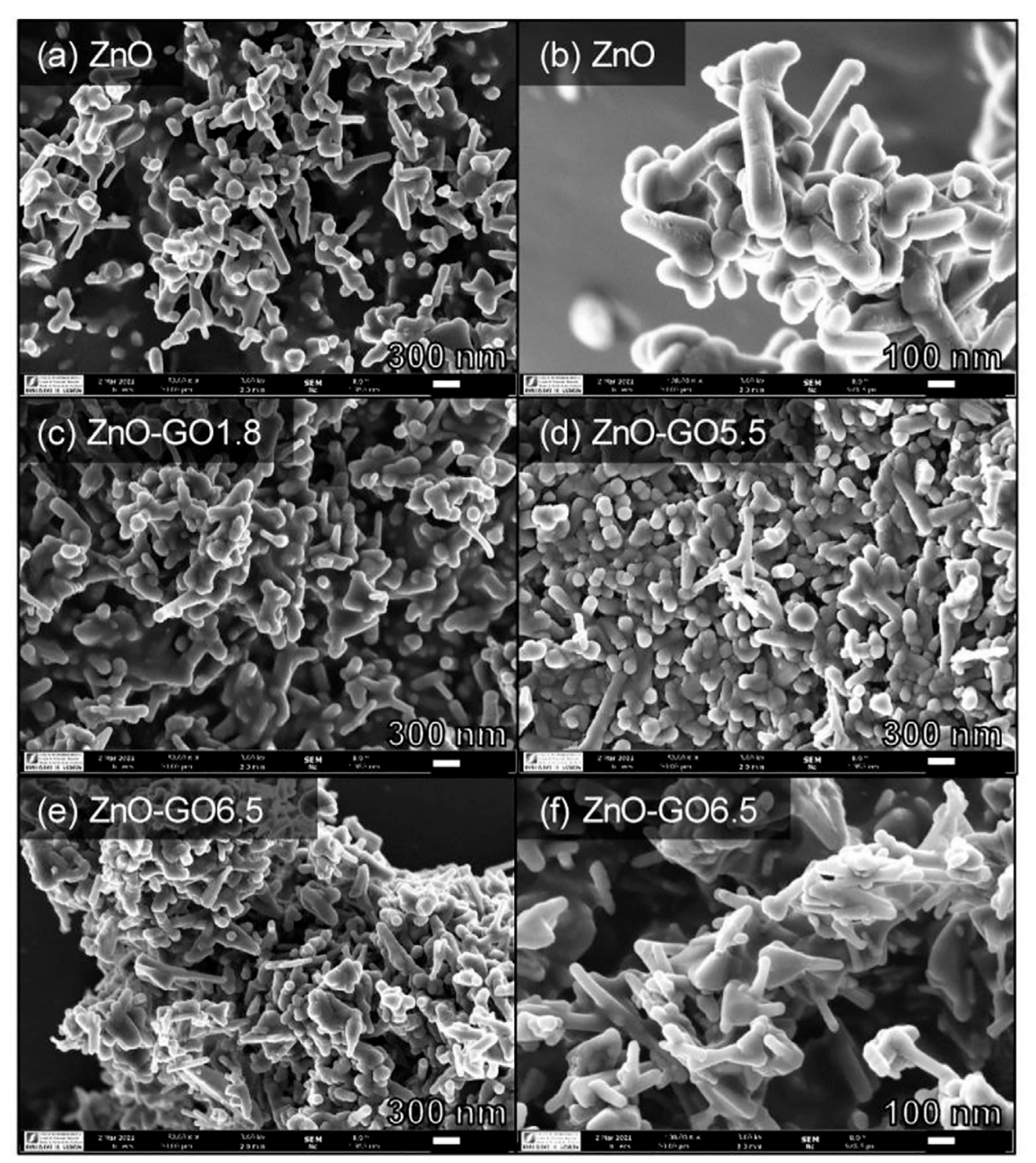

FIGURE 8 | SEM images of ZnO-GO composites at various GO loading; (A, B) ZnO, (C) ZnO-GO1.8, (D) ZnO-GO5.5, and (E, F) ZnO-GO6.5. Reproduce from Mirikaram et al. (2021)with MDPI permission.

lifespan. The $\mathrm{GO}$ was nanohybridized with a range of metal oxides, including $\mathrm{ZnO}, \mathrm{TiO}_{2}, \mathrm{WO}_{3}, \mathrm{Fe}_{2} \mathrm{O}_{3}, \mathrm{SnO}_{2}, \mathrm{CuO}$, etc. Graphene derivatives inhibit corrosion, and the liquidation into the water of metal oxide nanoparticles, other than restricting the recombination of the electron hole, thereby extending the photocatalytic lifetime (Upadhyay et al., 2014). The waste-derived synthesized graphene derivatives composite with metal oxide can bring a major breakthrough in the photocatalysis field.

\section{Graphene Derivatives/Zinc Oxide Nanocomposite as Photocatalyst}

Researchers have spent a considerable effort over the past 2 decades in developing the photo-oxidation of organic dyes using GO-based $\mathrm{ZnO}$ nanocomposites. The development of heterostructures $\mathrm{GO} / \mathrm{ZnO}$ and $\mathrm{rGO}-\mathrm{ZnO}$ appears to reduce the recombinant losses and to extend the light response to visible light, which results in better photocatalytic functioning, particularly in visible light treatment (Atchudan et al., 2016). Table 1 highlights the $\mathrm{GO} / \mathrm{ZnO}$ and $\mathrm{rGO} / \mathrm{ZnO}$ nanocomposite photocatalysts for organic pollutants, especially for the technique of synthesis, shape of photocatalysts, as well as for the photocatalyst conditions and performance, described in literature. This section includes a number of intriguing nanocomposites $\mathrm{GO} / \mathrm{ZnO}$ for organic dyes photo-oxidation.

Posa et al. have synthesized $\mathrm{GO} / \mathrm{ZnO}$ nanocomposites, utilizing a simple wet chemical approach for effective photomineralization under sunshine (Posa et al., 2016). Related to the development of the $\mathrm{GO} / \mathrm{ZnO}$, which increased the lifespan of transporters, and the excitation of the dyes as the visible light sensitizing, the extraordinary photocatalytic activity of the nanocomposites. It was due to the increased effectiveness of the load segregation of electric-hole carriers. The $\mathrm{GO} / \mathrm{ZnO}$ nanocomposites were created by the integration of $\mathrm{GO}$ (i.e., $186.5 \mathrm{~m}^{2} / \mathrm{g}$ ), which has more area than $\mathrm{GO} / \mathrm{ZnO}$ nanocomposites, for photocatalysts with highly approachable surfaces (e.g., $158.0 \mathrm{~m}^{2} / \mathrm{g}$ ). The $\mathrm{GO} / \mathrm{ZnO}$ nanocomposites preparation through solvothermal method was reported by Atchudan et al. (Atchudan et al., 2016). Before solvothermal impregnation, the $\mathrm{GO}$ and $\mathrm{ZnO}$ nanoparticles were produced by 

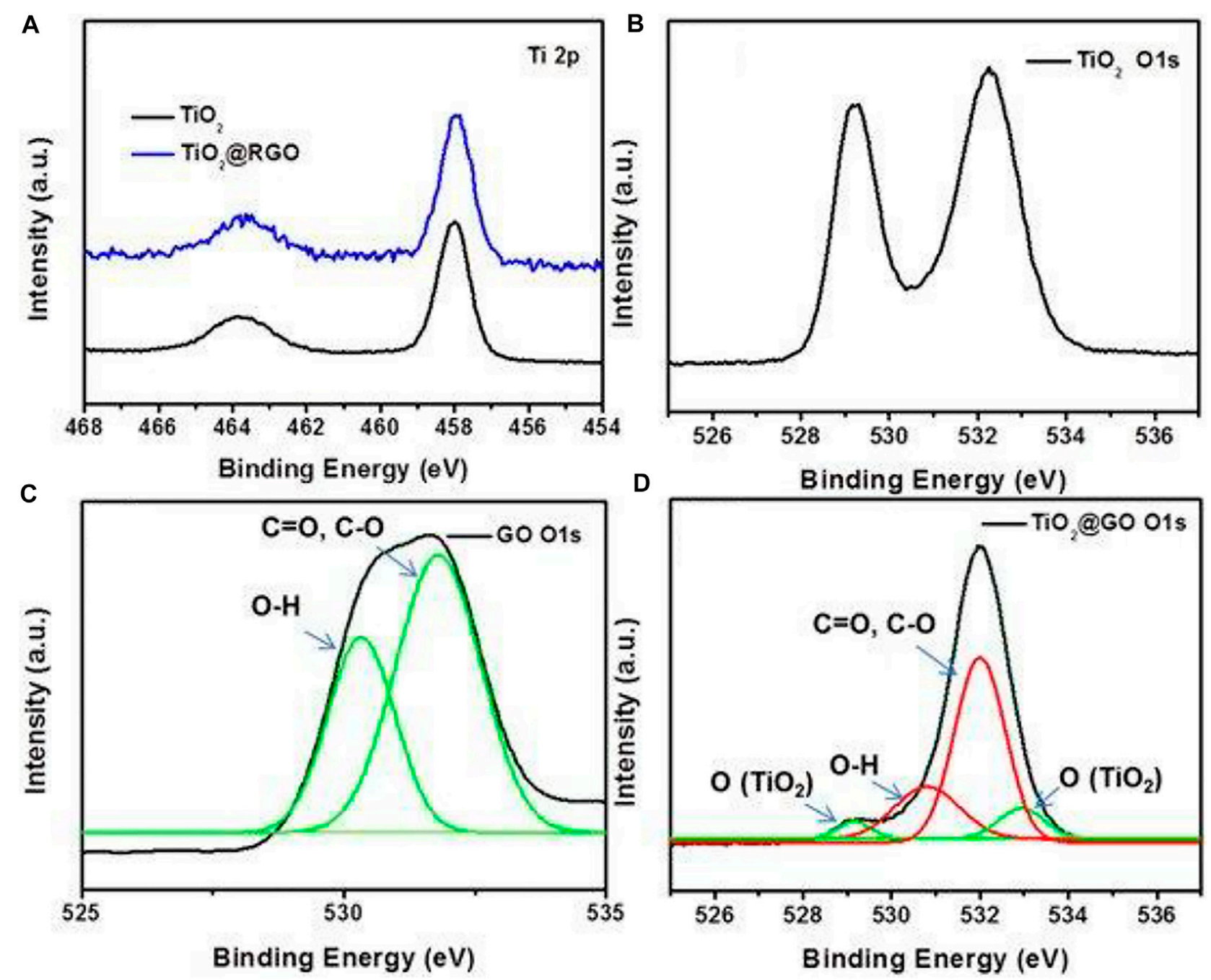

FIGURE 9|XPS spectra of (A) Ti 2p for $\mathrm{TiO}_{2}$ and $\mathrm{TiO}_{2}-\mathrm{GO}$, XPS spectra of $\mathrm{O}$ 1s for (B) $\mathrm{TiO}_{2}$, (C) $\mathrm{GO}$ and (D) TiO ${ }_{2}-\mathrm{GO}$. Reproduced from Shi et al., 2021 with MDPI permission.

Hummers' methods and thermal oxidation. These combinations have been efficacious in photodegradation of methylene blue dye with UV light radiation, $98.5 \%$ after 15 min of irradiation. It was carried out due to the enhanced light absorption and decreased electron hole combination, which has been caused by the development of a $\mathrm{GO} / \mathrm{ZnO}$ heterostructure. On the other hand, Qin et al. prepared the $\mathrm{rGO} / \mathrm{ZnO}$ microspheres nanocomposite with an easy solution for the degeneration by UV light of Methylene Blue (Qin et al., 2017). The $\mathrm{ZnO}$ microspheres were morphological and composed of $\mathrm{ZnO}$ nanorods with uniform distribution of about $30 \mathrm{~nm}$ in diameter and roughly $150 \mathrm{~nm}$ in length. Compared to $\mathrm{ZnO}$, the increased photocatalytic activity of $\mathrm{ZnO}$-filling $\mathrm{ZnO}-\mathrm{rGO}$ nanocomposites was due to the decrease in the recombinants process. Moreover, Liu et al. have manufactured $\mathrm{rGO} / \mathrm{ZnO}$ nanocomposites based on well-circulated $\mathrm{ZnO}$-nanocrystals on rGO using a simple microwave-assisted method in anhydrous medium (Y. Liu et al., 2012). In the decolorization of several dyes (methylene blue and rhodamine B), the produced nanocomposites showed better photocatalytic activity in visible light radiation. The authors predicted a considerable reduction in the process of recombination due to the creation of $\mathrm{rGO} / \mathrm{ZnO}$ nanocomposites that can turnover considerably from photocatalytic efficiency of dyes (Yaqoob, Noor, et al., 2020).

\section{Graphene Derivatives/ $/ \mathrm{TiO}_{2}$ Nanocomposite as Photocatalyst}

$\mathrm{TiO}_{2}$ has been investigated for the treatment of water. It is one of the most popular and commonly utilized photocatalysts. It is preferable used as compared to other metal oxides due to its important properties such as safety, nontoxic, inexpensive, and chemically stable (Hunge et al., 2020). Similar to $\mathrm{ZnO}$, its photocatalytic activity is solely confined to the ultra-violet region which is only $4 \%$ of the total solar energy and thus becoming a major problem (Yadav et al., 2021). This is due to 
TABLE 1 | Confrontation of $\mathrm{GO} / \mathrm{ZnO}$ and $\mathrm{rGO} / \mathrm{ZnO}$ nanocomposite photocatalytic in the photo-oxidation of organic dyes with synthesis, and photo-catalytic performance.

\begin{tabular}{|c|c|c|c|c|c|}
\hline Photocatalyst & ZnO morphology & Synthesis method & Targeted pollutant & Removal (\%) & Ref. \\
\hline $\mathrm{GO} / \mathrm{ZnO}$ & Nanoparticles & Solvothermal & Congo Red & 68 & Atchudan et al. (2017) \\
\hline $\mathrm{GO} / \mathrm{ZnO}$ & Nanoparticles & Solvothermal & Methylene blue & 98.5 & Atchudan et al. (2016) \\
\hline $\mathrm{GO} / \mathrm{ZnO}$ & Nanoparticles & Solvent-free synthesis & Methylene blue & 100 & Lonkar et al. (2019) \\
\hline $\mathrm{GO} / \mathrm{ZnO}$ & Nanorod films & Hydrothermal & Methylene blue & 99 & Rokhsat and Akhavan, (2016) \\
\hline $\mathrm{GO} / \mathrm{ZnO}$ & Microspheres & Simple solution method & Methylene blue & 99 & Qin et al. (2017) \\
\hline $\mathrm{rGO} / \mathrm{ZnO}$ & Nanorods & Chemical etching and hydrolysis Method & Rhodamine B & 92 & Zhao et al. (2017) \\
\hline $\mathrm{rGO} / \mathrm{ZnO}$ & Nanorods & Hydrothermal & Methyl orange & 93 & Ranjith et al. (2017) \\
\hline $\mathrm{GO} / \mathrm{ZnO}$ & Nanoparticles & Simple solution approach & Safranin $\mathrm{T}$ & 100 & Nenavathu et al. (2018) \\
\hline $\mathrm{GO} / \mathrm{ZnO}$ & Nanoparticles & Solvothermal & Methylene blue & 80 & Jabeen et al. (2017) \\
\hline $\mathrm{GO} / \mathrm{ZnO}$ & Film & Atomic layer deposition & Methyl orange & 84 & Justh et al. (2018) \\
\hline $\mathrm{GO} / \mathrm{ZnO}$ & Nanoparticles & Sol-gel & Rhodamine B & 99 & Yao et al. (2016) \\
\hline $\mathrm{GO} / \mathrm{ZnO}$ & Nanoparticles & Ultrasonication + Hydrothermal & Methylene blue & 99 & Mohamed et al. (2019) \\
\hline $\mathrm{rGO} / \mathrm{ZnO}$ & Spindle & Hydrothermal & Methylene blue & 93 & Prabhu et al. (2018) \\
\hline $\mathrm{rGO} / \mathrm{ZnO}$ & Lotus & Sol-gel & Phenol & 86 & Yadav et al. (2019) \\
\hline $\mathrm{rGO} / \mathrm{ZnO}$ & Nanosheets & Hydrothermal & Methylene blue & 100 & Liu et al. (2020) \\
\hline $\mathrm{rGO} / \mathrm{ZnO}$ & Nanoparticles & Hydrothermal & Methylene blue & 100 & Van Tuan et al. (2020) \\
\hline $\mathrm{rGO} / \mathrm{ZnO}$ & Nanowires & Electrodeposition & Methylene blue & 23 & Pruna et al. (2017) \\
\hline
\end{tabular}

TABLE 2 | Summary of graphene/TiO ${ }_{2}$ nanocomposite for photodegradation of water pollutants.

\begin{tabular}{|c|c|c|c|c|}
\hline Photocatalyst & $\mathrm{TiO}_{2}$ morphology & Targeted pollutant & Removal (\%) & Ref. \\
\hline Graphene/ $/ \mathrm{TiO}_{2}$ nanocomposite & Nanoparticles & Methylene blue & 90 & Cho et al. (2015) \\
\hline Graphene/ $/ \mathrm{TiO}_{2}$ nanocomposite & Nanoparticles & Methylene blue & 100 & Zhang et al. (2017) \\
\hline Graphene $/ \mathrm{TiO}_{2}$ composite & - & Methylene blue & 85 & Divya et al. (2017) \\
\hline $\mathrm{rGO} / \mathrm{TiO}_{2}$ & Nanoparticles & Methylene blue & 92 & Sohail et al. (2017) \\
\hline Graphene quantum dots $/ \mathrm{TiO}_{2}$ nanocomposite & Nanoparticles & Methylene blue & 100 & Gupta et al. (2015) \\
\hline $\mathrm{rGO} / \mathrm{TiO} 2$ & Anatase and nanofibers & Methyl orange & 97 & Lavanya et al. (2017) \\
\hline Graphene-pasted-TiO2 composite & Spheres & Methyl orange & 95 & Xu et al. (2016) \\
\hline $\mathrm{GO} / \mathrm{TiO}_{2}$ nanocomposite & Nanoparticles & Methyl orange & 88 & Zhang et al. (2017) \\
\hline $\mathrm{rGO} / \mathrm{TiO}_{2}$ nanocomposite & Nanoparticles & Methyl orange & 80 & Zhang et al. (2017) \\
\hline $\mathrm{rGO} / \mathrm{TiO}_{2}$ nanocomposite & Nanotubes & Methyl orange & 100 & Zhao et al. (2015) \\
\hline $\mathrm{rGO} / \mathrm{TiO}_{2}$ & - & Rhodamine B & 100 & Chen et al. (2017) \\
\hline $\mathrm{rGO} / \mathrm{TiO}_{2}$ & Nanosheet & Rhodamine B & 83 & Wang et al. (2017) \\
\hline $\mathrm{rGO} / \mathrm{TiO}_{2}-\mathrm{Au}$ nanocomposite & Nanoparticles & Rhodamine B & 100 & Wang et al. (2017) \\
\hline Core-shell $\mathrm{TiO}_{2} /$ Graphene & - & Rhodamine B & 100 & Biris et al. (2016) \\
\hline $\mathrm{rGO} / \mathrm{TiO}_{2}$ & Nanoflower & Rhodamine B & 100 & Kim et al. (2016) \\
\hline $\mathrm{rGO} / \mathrm{TiO}_{2}$ & Nanotubes & Rhodamine B & 100 & Liu et al. (2016) \\
\hline Graphene/TiO 2 & Nanoparticles & Methylene blue & 100 & Yang et al. (2016) \\
\hline Graphene/TiO 2 & Nanoparticles & Methylene blue & 100 & Suave et al. (2017) \\
\hline Graphite $/ \mathrm{TiO}_{2}$ & - & Methylene blue & 100 & Baldissarelli et al. (2015) \\
\hline $\mathrm{TiO}_{2} /$ Graphene & Flocculent & Methyl orange & 70 & Han et al. (2015) \\
\hline
\end{tabular}

the fact that $\mathrm{TiO}_{2}$ possess a wide bandgap energy $(3.2 \mathrm{eV})($ Koli et al., 2017; Delekar et al., 2018). A number of strategies have been explored to narrow the gap in the bands to make them active in an area of visibility such as doping, insertion of defects, and combination of these with electron acceptors. One of the most commonly researched of these techniques, along with electron acceptors. Graphene was also investigated as a molecule for electron acceptor composites with $\mathrm{TiO}_{2}$, and several composites with $\mathrm{TiO}_{2}$ /graphene reported in different investigations are included in Table 2.

A combination of nanoparticles of metal oxide and graphene derivatives, resulted in the formulation of new valence bands which is responsible to reduce the metal oxide band gap by hybridizing the atomic orbits. The amount of metal oxide loading on the graphic supporting material needs to be carefully adjusted for an effective catalyst-support interaction (Upadhyay et al., 2014). Indeed, in deciding on the photocatalytic activity of the combinations, the percentage of the graphene content plays a major role and changes in the quantity of graphene have a significant impact on the performance of the resultant catalyst. In general, the increase in composite graphene content increases photocatalysis, but an increase of graphene content above some threshold limit may lead to the decrease the photocatalytic activity by increasing the absorption and spread of photons by the excess carbon content in the composite. In order to achieve maximal photocatalytic activity, Wang et al. examined the impact of graph loading on $\mathrm{TiO}_{2}$-graphene composites and adjusted threshold weights for graphene (0.05 wt\%) (Wang et al., 2012). 
The photocatalytic activity of the hybrid material intensely coupled $\mathrm{TiO}_{2}$ with graphene promotes load separation and delayed recombination. $\mathrm{TiO}_{2}$ can provide a significantly more effective photocatalyst for hybrid graphene or graphene in situ on $\mathrm{TiO}_{2}$. For $\mathrm{TiO}_{2} /$ graphene-like carbon structure production, Wang et al. established a technique which shows over 2.5 times increased methylene blue dye photodegradation as compared with Pristine Degussa P25 $\mathrm{TiO}_{2}$ (Wang et al., 2010). Liang et al. described the development, using hydrolyze combined hydrothermal treatments, of $\mathrm{TiO}_{2}$ nanocrystals in a steady growth on the graphene oxide substrate (Liang et al., 2010). The $\mathrm{GO} / \mathrm{TiO}_{2}$ hybrids were developed to demonstrate three-fold photocatalytic activity as compared to $\mathrm{P} 25 \mathrm{TiO}_{2}$ for the degradation of Rhodamine $\mathrm{B}$ dye. In another work, Min et al. effectively produced $\mathrm{N}$ doped $\mathrm{TiO}_{2}$ composites with graphene and examined their benzoic acid degradation photocatalytic activity (Min et al., 2013). The $\mathrm{TiO}_{2}$ /graphene composites were doped with nitrogen and show increased photocatalytic activity as compared with pure $\mathrm{TiO}_{2}$-graphene composites that were subsequently ascribed to the increased $\mathrm{N}-\mathrm{TiO}_{2}$ /graphene composite response in the visible area. Additionally, $\mathrm{TiO}_{2} /$ graphene composite surface modifiers may also increase the photocatalysis of the composite, using metal ions such as $\mathrm{Pt}$, Ag, Fe, Au, etc. (Ahmad et al., 2021; Yaqoob et al., 2020). These metals are found to extend the life of charging carriers to capture excited electrons in order to decrease the recombination of charging carriers further.

\section{Nanocomposites of Graphene Derivatives With Other Metal Oxide as Photocatalyst}

Other than $\mathrm{TiO}_{2}$ and $\mathrm{ZnO}$, other metal oxide like $\mathrm{WO}_{3}, \mathrm{Fe}_{2} \mathrm{O}_{3}$, $\mathrm{CuO}$ and $\mathrm{SnO}_{2}$ are considered as nontoxic photocatalyst for pollutant removal due to their low-cost, fast response and recovery time. $\mathrm{WO}_{3}$, is an n-type semiconductor, activated under visible light irradiation having small bandgap (2.4-2.8 eV) that makes it a suitable catalyst for degrading organic compounds (Yadav et al., 2021). Further, $\mathrm{Fe}_{2} \mathrm{O}_{3}$ is another example of n-type semiconductor with narrow bandgap energy of $2.0-2.2 \mathrm{eV}$ and it exhibits a wide photoelectrochemical response that is useful for photocatalysis (Botsa et al., 2020). In the case of $\mathrm{CuO}$, it is a p-type semiconductor material with good optical and catalytic properties. It has a low bandgap energy of around $1.2-1.7 \mathrm{eV}$ (Wang et al., 2020). On the other hand, $\mathrm{SnO}_{2}$ is an n-type semiconductor with a wide bandgap energy of $3.6 \mathrm{eV}$ (Choudhari et al., 2020). It has a rutile crystal structure and very identical to $\mathrm{TiO}_{2}$. Due to the wide bandgap, $\mathrm{SnO}_{2}$ only active under UV light and very limited under the visible light (Shyamala and Gomathi Devi, 2020). Each type of these metal oxides has their own advantages and limitations. In some cases, combining them could minimize their limitation and subsequently enhanced their photocatalytic efficacy. Table 3 displays some examples of reported nanocomposites of graphene derivatives with other metal oxide with targeted pollutants and their removal performance.

\section{MECHANISM OF PHOTOCATALYTIC DEGRADATION}

As far as the mechanism of photocatalytic degradation is concern, the radical species that generated in the semiconductor photoexcitation played an important role for organic pollutant's degradation. The pictorial illustration of degradation using graphene/ $/ \mathrm{TiO}_{2}$ as a photocatalyst in the presence of visible light is presented in Figure 10.

The most crucial steps concerned in this degradation process can be pictured in the steps, are mentioned below (Eqs. 5-11) (Qi et al., 2017).

$$
\begin{gathered}
\mathrm{h}^{+}+\mathrm{H}_{2} \mathrm{O} \rightarrow \mathrm{H}^{+}+\mathrm{OH}^{-} \\
\mathrm{h}^{+}+\mathrm{OH}^{-} \rightarrow \mathrm{OH}^{\bullet} \\
\mathrm{e}^{-}+\mathrm{O}_{2} \rightarrow \mathrm{O}_{2}^{\bullet} \\
2 \mathrm{e}^{-}+\mathrm{O}_{2}+\mathrm{H}_{2} \mathrm{O} \rightarrow \mathrm{H}_{2} \mathrm{O}_{2} \\
\mathrm{e}^{-}+\mathrm{H}_{2} \mathrm{O}_{2} \rightarrow \mathrm{OH}^{\bullet}+\mathrm{OH}^{-}
\end{gathered}
$$$$
\text { Photons }(h v)+\text { semiconductor } \rightarrow h^{+}(V B)+e^{-}(C B)
$$

Organic contaminant $+\mathrm{OH}^{\bullet}+\mathrm{O}_{2} \rightarrow \mathrm{CO}_{2}+\mathrm{H}_{2} \mathrm{O}$

$$
+ \text { other degraded products }
$$

The mechanism also depends on certain conditions of experiment. The degradation mostly depends on the excited electron with hole inside the semiconductor. A variety of semiconductors are being employed with mostly nanosized state owing to increases of surface area and effect of quantum size favorably (Samadi et al., 2019). Different forms of $\mathrm{ZnO}$ or $\mathrm{TiO}_{2}$ with either metal or non-metal doping can be applied in the various types of pollutant degradation due to stability, non-toxic properties and capability in degradation of $\mathrm{ZnO}$ and $\mathrm{TiO}_{2}$ (Lum et al., 2020). Nevertheless, the application of this compound has been restricted for the degradation of organic pollutant commercially because of the possible variables related to experiment including, light used and separation treatment technique. The $\mathrm{TiO}_{2}$ was the most popular photocatalyst material in the early days. However, nowadays, more research at a higher level has been required in order to explore better alternatives rather than $\mathrm{TiO}_{2}$ in photocatalytic degradation application. Another compound can be better employed than $\mathrm{TiO}_{2}$ such as $\mathrm{ZnO}$ and their composite-based material (Gebreslassie et al., 2013). The reasonable reason for this choice is believed to be the $\mathrm{TiO}_{2}$ high absorption coefficient. The intensity of semiconductor scattering on the surface can vary and thus, the most variable is more accounted for the roughness factor value on the surfaces. Furthermore, the absorption coefficient value depends on different physical features such as roughness of surface, the size particle of inherent valence electrons occupancy added and the occupied wave functions. However, $\mathrm{ZnO}$ and $\mathrm{TiO}_{2}$ can be an ideal approach for photocatalysis in the form of composites with other materials.

\section{FACTOR AFFECTING THE PHOTOCATALYSIS PROCESS}

There are several factors which hold direct effects on the performance of photocatalysis to degrade/decolorize the 
TABLE 3 | Summary of graphene derivatives with $\mathrm{WO}_{3}$ and $\mathrm{Fe}_{2} \mathrm{O}_{3}$ nanocomposites for photodegradation of dye pollutants.

\begin{tabular}{|c|c|c|c|c|}
\hline Photocatalyst & Metal oxide morphology & Targeted pollutant & Removal (\%) & Ref. \\
\hline rGO/ $\mathrm{WO}_{3}$ nanoplate & Nanoparticles & Congo red & 94 & Yadav et al. (2021) \\
\hline rGO/ $\mathrm{WO}_{3}$ nanocomposite & Nanoparticles & Methylene blue & 82 & Kodarkar et al. (2021) \\
\hline $\mathrm{rGO} / \mathrm{NO}_{3}$ nanocomposite & Nanorod & Rhodamine B & 96 & Govindaraj et al. (2021) \\
\hline Indigo-rGO/ $\mathrm{NO}_{3}$ nanocomposite & - & Methylene blue & 80 & Khan et al. (2019) \\
\hline $\mathrm{GO} \mathrm{NO}_{3}$ nanocomposite & Nanorod & Methylene blue & 83 & Hu et al. (2018) \\
\hline $\mathrm{GO} / \alpha-\mathrm{Fe}_{2} \mathrm{O}_{3}$ nanocomposite & Nanoparticles & Methylene blue & 90 & Mandal et al. (2018) \\
\hline Graphene/a- $\mathrm{Fe}_{2} \mathrm{O}_{3}$ & - & Rhodamine B & 99 & Frindy and Sillanpää, (2020) \\
\hline Graphene $/ \mathrm{Fe}_{2} \mathrm{O}_{3} / \mathrm{CuO}$ & - & Methylene blue & 94 & Nuengmatcha et al. (2019) \\
\hline Graphene/ $/ \mathrm{Fe}_{2} \mathrm{O}_{3} / \mathrm{TiO}_{2}$ nanocomposite & - & Rhodamine B & 97 & Zhang et al. (2018) \\
\hline $\mathrm{GO} / \mathrm{Fe}_{2} \mathrm{O}_{3} / \mathrm{SnO}_{2}$ nanocomposite & - & Methylene blue & 98 & Botsa et al. (2020) \\
\hline $\mathrm{rGO} / \mathrm{SnO}_{2}$ & Aerogel & Methyl orange & 84 & Kim et al. (2019) \\
\hline rGO-SnO2 & - & Rhodamine B & 98 & Kim et al. (2019) \\
\hline
\end{tabular}

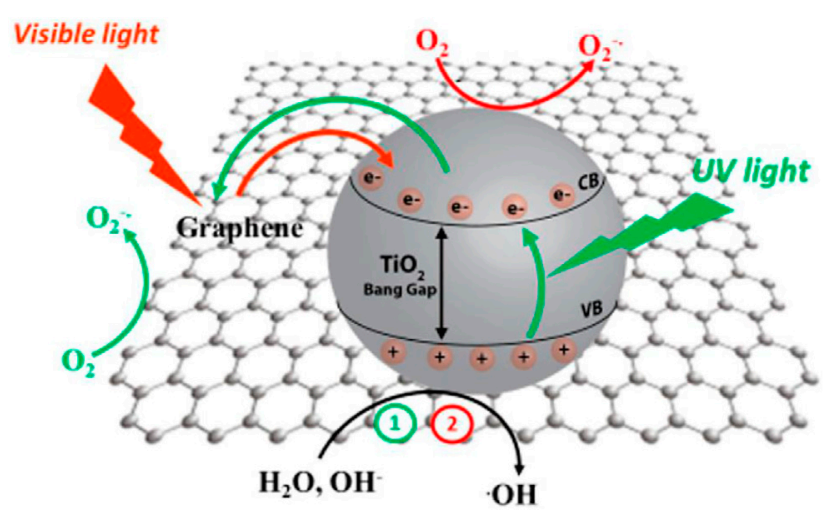

FIGURE 10 | Mechanism of photodegradation by using graphene/ $\mathrm{TiO}_{2}$ as a photocatalyst in the presence of visible light (Adapted from Giovannetti et al. (2017) with MDPI permission).

pollutants from water resources. Some of the most important are mentioned here to show their significance in photocatalysis.

\section{Photocatalyst Loading}

The photocatalyst loading effect in particular $\mathrm{ZnO}$ or $\mathrm{TiO}_{2}$ doped carries a substantial effect on performance of photocatalytic behaviour. In literature, different photocatalyst studies have been already investigated to observe their loading effect on the entire performance of pollutant's degradation (Zhang et al., 2017). After extensive literature review, the conclusion demonstrated that the photodegradation is relative to the loaded catalyst until it achieved an elevated condition. This phenomenon corresponds to the high photocatalyst quantity which raises the entire active reaction spots and $\mathrm{ZnO} / \mathrm{GO}$ photocatalyst surface area (Rajamanickam and Shanthi, 2016; Vaiano et al., 2018). As an effect, the amount of superoxide radicals and hydroxyl increased which enables the degradation of pollutants. Therefore, the percentage of degradation was improved. Though, the photodegradation percentage reduces at high concentration loadings of the catalyst when the dose was at optimized concentration due to screening effects and UVlight scattering influence. Furthermore, a high amount of photocatalyst promotes the agglomeration contact which may lead to reduced catalytic surface area. This surface area is accessible for UV absorption and chemical adsorption, which ultimately decreased the catalytic effectiveness. One more effect observed is solution's turbidity which also increases as a result of high catalyst loading. This singularity prevents the dispersion of light into mediums. Therefore, the photo-activated suspension volume reduces and thus degradation rate is lower respectively (Ng and Cheng, 2016; Lonkar et al., 2019). This phenomena recommended that the optimized photocatalyst mass must be investigated to avoid excessive dose of catalyst and certify a supreme photons absorption.

\section{Structure of Photocatalyst}

The photodegradation efficiency can be improved by the modification in the development of $\mathrm{ZnO}$ and $\mathrm{TiO}_{2}$ structure. Recently, $\mathrm{ZnO}$ or $\mathrm{TiO}_{2}$ nano-based structure has received an excessive attention in photocatalysis study due to the presence of excellent physicochemical properties as well as structural morphology (Duan et al., 2020; Mohd Adnan et al., 2020; Zouhier et al., 2020). The $\mathrm{ZnO}$ or $\mathrm{TiO}_{2}$ NPs is available in several morphologies like nanosheets, nanobelts, nanorods, nano dumb bells, nanowires, nanospiral disks, neotheropods and nanoflowers. These all forms are different in properties and morphologies than bulk $\mathrm{ZnO}$ or $\mathrm{TiO}_{2}$ material. The $\mathrm{ZnO}$ and $\mathrm{TiO}_{2}$ nanostructured morphologies contain a nano range particle size with high surface area. This high surface area offers excellent physical and chemical properties (Giovannetti et al., 2017; Lum et al., 2020; Zhang et al., 2017). The nano range $\mathrm{ZnO/}$ $\mathrm{TiO}_{2}$ holds a unique surface and quantum effect. Assi et al. studied the $\mathrm{ZnO}$ nanorod for methylene blue (MB) degradation via photocatalysis (Assi et al., 2015). The study specified that the high surface area of $\mathrm{ZnO}$ nanorods produces improved photodegradation productivity than nanorods with low surface area. An innovative $\mathrm{ZnO}$ or $\mathrm{TiO}_{2}$ nano range sheet was created for the Rhodamine $\mathrm{B}$ photodegradation via photocatalysis process. However, the $3 \mathrm{D}$ fleecy-based structure proposes several reaction active sites and large surface area for operation (Lai et al., 2010). The Rhodamine B removal by photocatalytic reaction showed a higher rate of photodegradation than many other nanostructures catalysts 
due to presence of optimized surface area and enhanced isolation competence for holes and electrons.

\section{Oxidizing Species}

The excellent oxidizing species addition, such as potassium peroxydisulfate $\left(\mathrm{K}_{2} \mathrm{~S}_{2} \mathrm{O}_{8}\right)$ and hydrogen peroxide $\left(\mathrm{H}_{2} \mathrm{O}_{2}\right)$ into suspension of $\mathrm{ZnO} / \mathrm{TiO}_{2}$ is common procedure used to increase the photo-oxidation rate (Wahab et al., 2019). Besides that, it is assumed that hydrogen peroxide has multifunction during the photocatalytic degradation process. For examples, it can draw electron away from conduction band which lead towards separation of charge promotion and hydrogen peroxide also generate hydroxyl radicals as shown below in Eqs. 12, 13.

$$
\begin{gathered}
\mathrm{H}_{2} \mathrm{O}_{2}+\mathrm{e}^{-} \rightarrow \mathrm{OH}^{-}+\mathrm{OH}^{\bullet} \\
\mathrm{H}_{2} \mathrm{O}_{2}+\mathrm{O}_{2}^{-} \rightarrow \mathrm{OH}^{-}+\mathrm{OH}^{\bullet}+\mathrm{O}_{2}
\end{gathered}
$$

When concentration of hydrogen peroxide is higher than concentration critical, it may act like hole or else scavenger for $\mathrm{OH}^{-}$or become reactive towards $\mathrm{ZnO} / \mathrm{TiO}_{2}$ in forming peroxyl groups that are unfavourable to photocatalytic reaction (Pathak et al., 2017). Bizani et al. stated in their report that oxidant addition like $\mathrm{H}_{2} \mathrm{O}_{2}$ proved to become more effective in the degradation of pollutants rather than $\mathrm{K}_{2} \mathrm{~S}_{2} \mathrm{O}_{8}$ experimentally, even though their efficiency in degradation could be vice versa. Moreover, intermediates of organic pollutants had been shown to possess more toxicity when using $\mathrm{K}_{2} \mathrm{~S}_{2} \mathrm{O}_{8}$ rather than degradation of organic pollutants by photocatalysis technique. It involves $\mathrm{H}_{2} \mathrm{O}_{2}$, which indicates efficiency of toxic removal and partial dissolved organic carbon (DOC) (Bizani et al., 2016).

\section{$\mathrm{pH}$}

The $\mathrm{pH}$ level is another key factor determining the degradation of organic compounds during photocatalytic reaction. In essence, $\mathrm{pH}$ has a substantial influence on the surface charge of catalyst, contaminant hydrolysis, oxidant and contaminant ionization degree (Hayati et al., 2018). The surface charge of the photocatalyst affected the adsorption properties of the cationic or anionic organic pollutant. Additionally, the $\mathrm{pH}$ of the solution influences the dominant oxidation species, whereby at lower and higher $\mathrm{pH}$ levels, holes and hydroxyl radicals were shown to be the most important oxidative species (Alamelu and Jaffar Ali, 2020). Another important parameter to comprehend is the point of zero charge ( $\mathrm{pzc}$ ); is a state in which the net surface charges of a catalyst is zero or neutral and falls within a specific $\mathrm{pH}$ level (Alkaim et al., 2014). The pzc determined the surface charge of catalysts, at which it is positively charge when the $\mathrm{pH}$ level is less than pzc and negatively charge beyond pzc (Yaqoob et al., 2020). Thus, finding the optimum $\mathrm{pH}$ condition is a crucial stage that could determine the degradation effectiveness of the catalysts.

\section{Temperature}

The photocatalysis degradation development may lead to functions at optimized temperature as well as distinctive pressure because the photonic activation carries direct effect on it. This is valuable for water sanitization behaviour and the thermal phase, can be omitted to preserve power (Lee et al., 2016).
Overall, high temperatures of reaction may improve the degradation rate of pollutants. Furthermore, it can decrease the adsorptive volumes of the reactant and liquified oxygen, it referred to the low photodegradation productivity (Kumar et al., 2020; Lum et al., 2020). So, an optimized condition is very necessary for better efficiency in presence of $\mathrm{ZnO} / \mathrm{GO}$ and $\mathrm{TiO}_{2} / \mathrm{GO}$ composites as photocatalysts.

\section{Light Wavelength}

The light wavelength also carries a straight effect on the performance of the photocatalysis process. In case of UV irradiation, it refers to the electromagnetic band which can be divided as UV-A1, UV-A2 and UV-A3 corresponding to its producing wavelength (Wang et al., 2013). The range of UVA1 is within $315-400 \mathrm{~nm}$ or $3.10-3.94 \mathrm{eV}$ while UV-A2 and UVA3 have a range $280-315 \mathrm{~nm}$ and $100-280 \mathrm{~nm}$ respectively. However, studies showed that the UV-A1 light offers enough light photons of synthesized $\mathrm{TiO}_{2}$ for 1,8-diazabicyclo (5.4.0) undec-7-ene photodegradation (Lee et al., 2016). Photocatalyst productivity is often high at $254 \mathrm{~nm}$ because of lower dispersion capacities of high energy photons, which enhances the electronhole pairs that are created accordingly for hazardous pollutant decompositions (Samadi et al., 2016).

\section{STUDIES OF INTERMEDIATE PRODUCTS FORMED DURING PHOTOCATALYTIC DEGRADATION OF ORGANIC POLLUTANTS}

During degradation, organic pollutants are decomposed or degraded into a number of products, whereas these pollutants are completely destroyed into water, carbon dioxide and certain inorganic ions when mineralization is carried out. The HPLC-MS or GC-MS was applied for analysis of degraded products following pollutant degradation by using the nanomaterials $\left(\mathrm{TiO}_{2}\right.$ or $\left.\mathrm{ZnO}\right)$ or graphene nanocomposites material in the presence of light. In this case, it is required to establish a relationship between parent compound and intermediates, weather these products are more harmful or less harmful than parent compounds utilizing the toxicity test in respect of the degradation products acquired (Yaqoob et al., 2020). Moreover, the idea of mineralization is alike with complete photodegradation which determines the formation of $\mathrm{CO}_{2}$, $\mathrm{H}_{2} \mathrm{O}$ and inorganic salts during the degradation of a pollutant (Horikoshi et al., 2004; Hu et al., 2006). Other minerals also may include such as sulphide, ammonia, sulfite, fluoride, sulphide, chlorine, phosphate, nitrite, etc. during mineralization of compounds (Rasolevandi et al., 2019). In general, as a result of generating a stable intermediate in process, the rate of mineralization is lower compared with degradation. A long irradiation for total organic carbon (TOC) elimination is thus expected to be required. Furthermore, in order to breakdown organic substances, the mineralization idea avoids generating unwanted products (Celine et al., 2017; Kim et al., 2017). The TOC is determined by an organic substance and quantified by a 

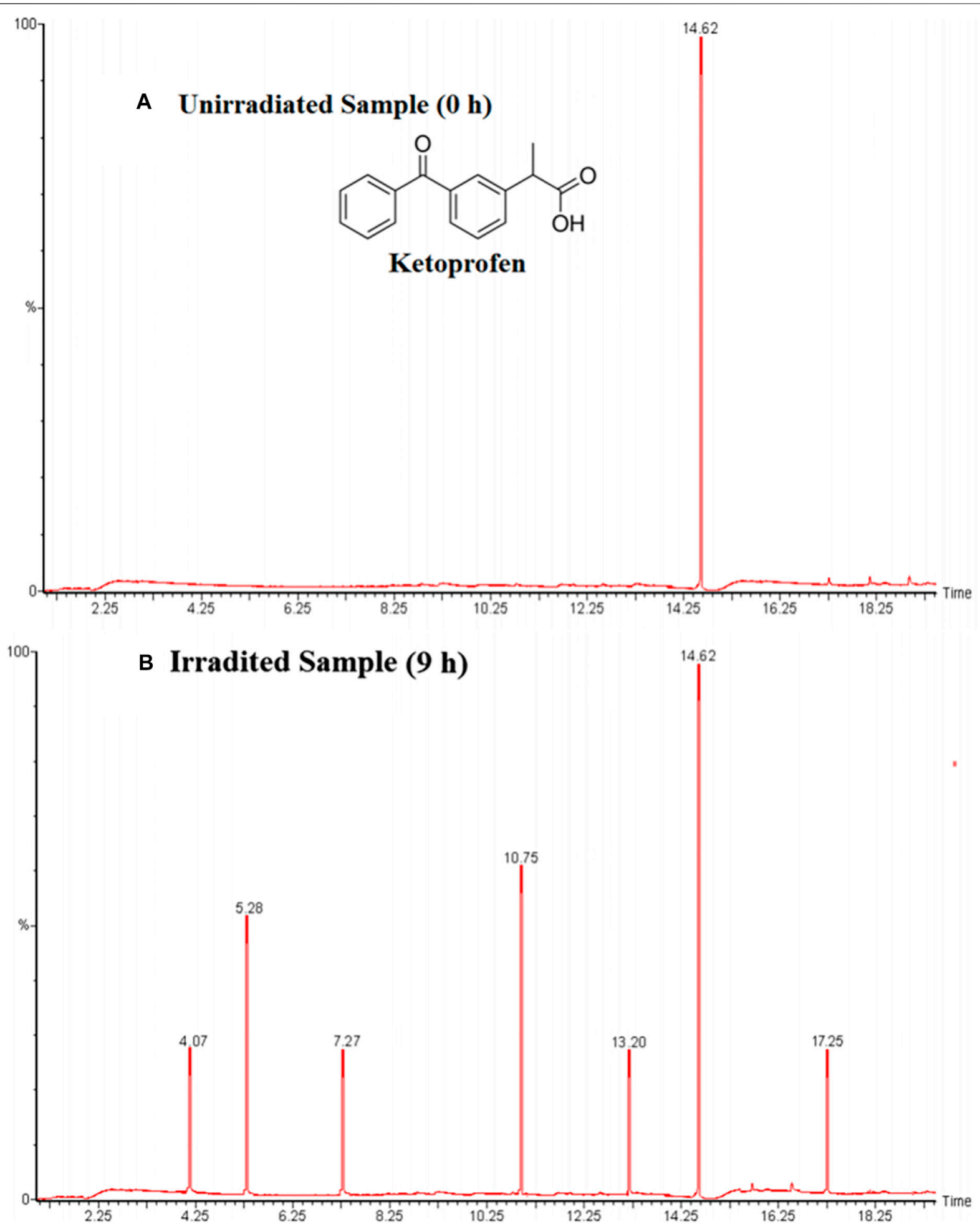

FIGURE 11 | Ketoprofen gas chromatogram analysis (A) unirradiated mixture (0 h), (B) irradiated mixture (9 h). (Adapted from Umar et al. (2019) with Springer permission).

TOC analyzer as the total quantity of confined carbons coupled with a photodegradation mechanism, show the probable method of pollutant mineralization.
Few examples which are previously discussed in literature such as Umar et al. studied the ketoprofen and chlorothalonil photodegradation pathway and found intermediate products 
<smiles>CC(C(=O)O)c1cccc(C([O-])c2ccccc2)c1</smiles>

1

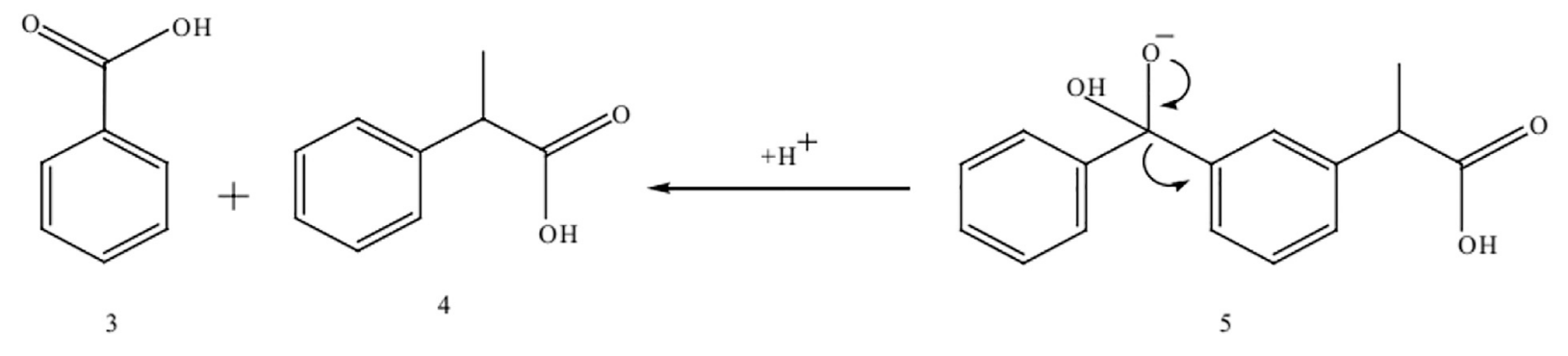

FIGURE 12 | The photocatalytic degradation mechanism of ketoprofen by using the Mn-doped $\mathrm{TiO}_{2}$ as photocatalyst (Adapted from Umar et al. (2019) with Springer permission).

by using the $\mathrm{Mn}$-doped $\mathrm{TiO}_{2}$ as a photocatalyst. Both analysis were analyzed using the GC-MS analytical techniques to detect the transitional outcomes produced during photooxidation (Umar et al., 2019). For example, a linear light-halogen lamp $(500 \mathrm{~W}, 9,500$ lumens) was used to irradiate the aqueous ketoprofen's solution $(0.2 \mathrm{mM})$ in the presence of Mn-doping $\mathrm{TiO}_{2}\left(3 \mathrm{~g} \mathrm{~L}^{-1}\right)$. The GC-MS analysis of an unirradiated and irradiated Ketoprofen solution showed that a single peak $(\mathrm{Rt}=$ 14,62) was obtained in first case and several peaks were appeared at retention times (Rt) 4.07, 5.28, 7.27, 10.75, 13.20 and 17.25 in later case as shown in Figures $7 \mathbf{B}, 11 \mathrm{~A}$, respectively. Based on the a pattern of mass fragments and molecular ions, two products at $\mathrm{Rt}=5.28$ and 10.75-min are described by such as benzoic acid (3) and 2-phenylpropanoic acid (4) and a possible route for the formation of these products can be seen in Figure 12 .

Similarly, in the case of chlorothalonil, photodegradation and intermediate products are shown in Figure 13. Analysis of the $9 \mathrm{~h}$ irradiated chlorothalonil mixture indicates the generation of a number of intermediate yields, two of which appear to be $R_{t}=14.15$ and 17.01 based on the pattern of mass fragmentation and molecular ions, were characterized as 4 and 3, which indicate a replacement of a cyanide group with a hydroxylated benzene ring group.

Similarly, the Basnet et al., studied the $\mathrm{Mn}-\mathrm{ZnO}$ composite as nano-photocatalyst in order to degrade the methylene blue (MB) dye solution (Basnet et al., 2021). The ESI-MS analyses examined the degradation process for MB solution. The spectrums ESI-MS obtained in 1) $0 \mathrm{~min} \mathrm{2)} 10 \mathrm{~min}(15 \mathrm{~min})$ 4) $20 \mathrm{~min}$ and the first
MB solution analysis of ESI-MS at 0 min shows the existence of molecular ion $\left(\mathrm{M}^{+}\right)$peak at $\mathrm{m} / \mathrm{Z}=284$. The peaks of $\mathrm{m} / \mathrm{Z}$ of 304-306, can be attributable to the center of MB, generated by a central aromatic heterocyclic aperture by the electromagnetic interaction between $\bullet \mathrm{OH}$ and sulfhydryl $\left(\mathrm{C}-\mathrm{S}^{+}=\mathrm{C}\right)$, leading to sulfoxide moiety production $(\mathrm{C}-\mathrm{S}(=\mathrm{O})-\mathrm{C})$ (Trandafilović et al., 2017; Yang et al., 2017). As a consequence of the contamination by Azure B and Azure A, as a result of partial de-methylating products of $\mathrm{MB}$, peaks with $\mathrm{m} / \mathrm{Z}$ values of 270 and 256 appeared (Depuccio et al., 2015). Low-intensity peaks in $\mathrm{m} / \mathrm{Z}=272,253$, $229,217,149,129,110$ after $10 \mathrm{~min}$ of light irradiation suggest breakup of molecules of MB (Molla et al., 2015). MB solution ESIMS analysis. These intermediates have also dissolved into many tiny intermediate molecular masses, which have eventually become $\mathrm{CO}_{2}, \mathrm{H}_{2} \mathrm{O}$, and inorganic salts (Gnaser et al., 2005). Based on this investigation, the aqueous MB dye solution has been suggested as a viable photocatalytic degradation route.

Furthermore, Rajamanickam et al. studied the degradation of 4nitrophenol by using the $\mathrm{ZnO}$ as photocatalyst (Rajamanickam and Shanthi, 2016). The formed intermediate products during the photocatalytic activities were detected by GC-MS analysis. Organic pollutant photodegradation processes can be carried out by the formation of hazardous intermediates which are poisonous greater than the initial molecules. Therefore, in photocatalytic degradation processes, it is essential to determine the identities of intermediates. In the photocatalytic degradation of 4-nitrophenol, an attempt has been made to find the intermediate intermediates forming in the 

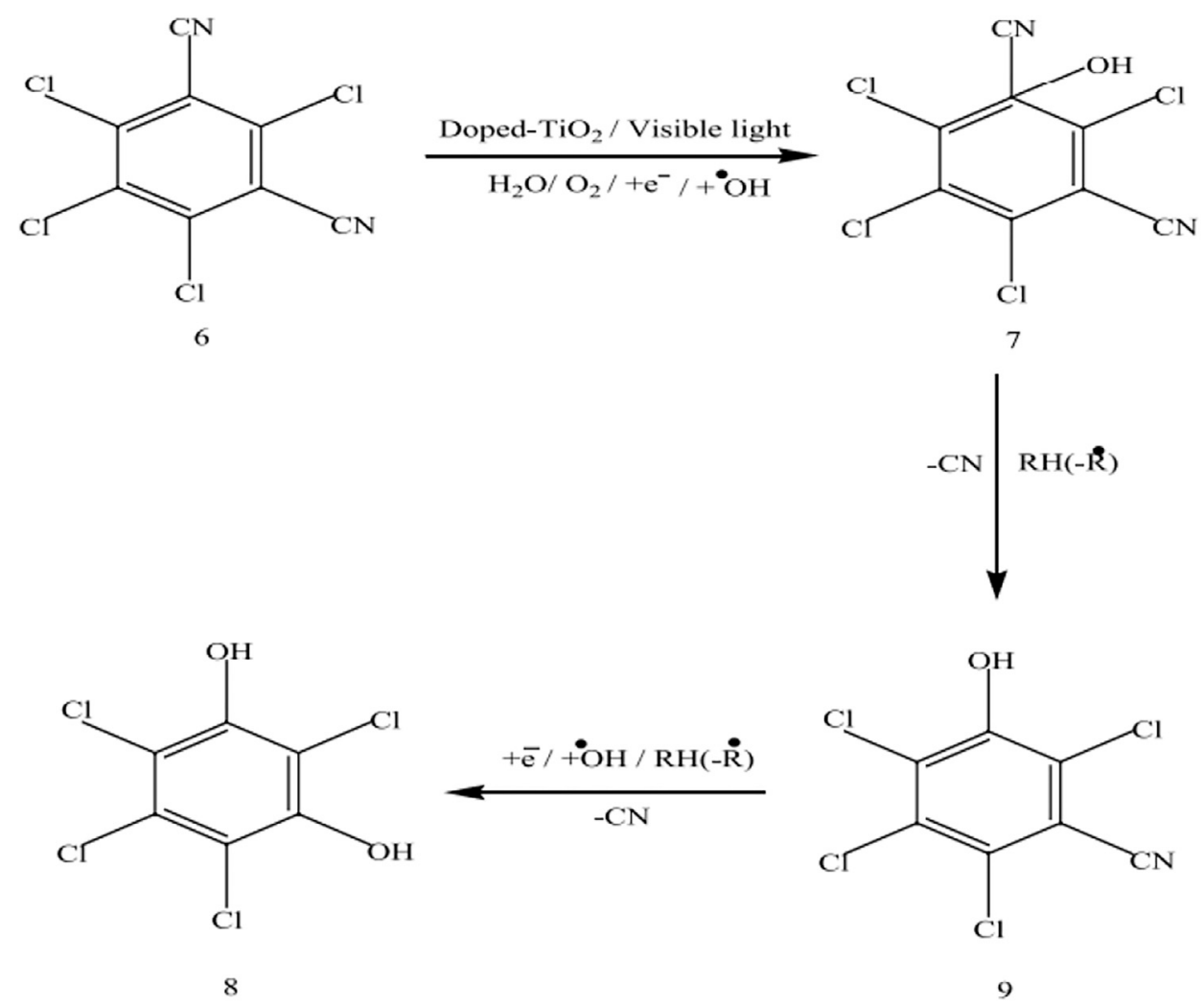

FIGURE 13 | The photocatalytic degradation mechanism of chlorothalonil by using the Mn-doped $\mathrm{TiO}_{2}$ as photocatalyst (Adapted from Umar et al. (2019) with Springer permission).

GC-MS analysis. After 30- and 60-min irradiation, GC-MS analysis of the solution was done. For retention periods of 18.0, 21.6, 27.9 and $29.4 \mathrm{~min}$, it was found four prevalent peaks. Eight products have been identified on the basis of their molecular ions and peaks for mass spectrometry.

Similarly, Cao et al., studied the routes for the formation of intermediate products (tetrabromobisphenol (TBBPA)-A) using the graphene- $\mathrm{TiO}_{2}$ composite as a photocatalyst. LC-MS was used to examine TBBPA intermediates in the photocatalytic degradation process. The photocatalytic degradation route of TBBPA was postulated based on the identified intermediates. The TBBPA decomposition was nearly $100 \%$ within 60 min with the formation of several intermediates, which were discovered by mass spectrometry. The mass spectra peak detected five major production ions at $465 \mathrm{~m} / \mathrm{z}, 401 \mathrm{~m} / \mathrm{z} .387 \mathrm{~m} / \mathrm{z}, 307 \mathrm{~m} / \mathrm{z}$ and $227 \mathrm{~m} / \mathrm{z}$, which were labeled Products A-E as presented in Table 4 (Cao et al., 2015).

By/ comparing the mass spectra with identified products from the degradation of TBBPA reported in previous published reports (Liu et al., 2013; Luo et al., 2010). The products A, C-E were identified as tribromobisphenol A (tri-BBPA), dibromobisphenol A (di-BBPA, two isomers), monobromobisphenol A (monoBBPA), and bisphenol A (BPA), respectively. Product B was discovered as isomers of 4-(2-(3,5-dibromo-4-hydroxyphenyl) propan-2-yl) benzene-1,2-diol (B1) and 3-bromo-5-(2-(3bromo-4-hydroxyphenyl) propan-2-yl) benzene-1,2-diol (B2).
The presence of the other intermediates was not found in this study, which is likely owing to their low concentration. The relative peak area of TBBPA and these intermediates was compared to determine their concentrations, as illustrated in Cao et al., article (Cao et al., 2015). The peak area of TBBPA vanished after $60 \mathrm{~min}$, which was consistent with the HPLC findings.

Furthermore, the peak area of the above-mentioned intermediates increased, implying the emergence of additional substrates, namely intermediates and products. The peak areas of product $\mathrm{A}$ and product $\mathrm{D}$ both increased initially and then declined, indicating that their appearance was dominating in the first stage. Then both Product A and Product D were rapidly degraded. After 30 and $10 \mathrm{~min}$, respectively, the peak areas of Product B1/B2 and Product E rose rapidly and reached a maximum. Then, when the irradiation duration was extended, they altered irregularly. Product E was not the end product, as can be observed, and it may have been converted into some tiny organic compounds that were not discovered in our investigation. On the other hand, over the entire $60 \mathrm{~min}$, the peak area of Product $\mathrm{C} 1 / \mathrm{C} 2$ rose steadily and constantly. It was discovered that Product $\mathrm{C} 1 / \mathrm{C} 2$ was most likely stable and/or that their creation was faster than their degradation during the procedure. Further, the potential mechanism for the photodegradation of TBBPA by graphene- $\mathrm{TiO}_{2}$ composites was postulated based on the preceding discussion of identified intermediates and prior studies. It was also noticed that TBBPA was photodegraded by three different pathways: debromination, 
TABLE 4 | TBBPA and its potential intermediates were found during the photodegradation process by graphene- $\mathrm{TiO}_{2}$ in the presence of UV light.

\begin{tabular}{|c|c|c|c|}
\hline Product & Compounds & Retention time/min & $\mathrm{m} / \mathrm{z}$ \\
\hline A & tri-BBPA & 1.433 & 465 \\
\hline B2 & 3-bromo-5-(2-(3-b romo-4-hydroxyphenyl)propan-2-yl)benzene-1,2-diol & 6.979 & 401 \\
\hline $\mathrm{C} 1$ & di-BBPA & 1.475 & 386 \\
\hline $\mathrm{C} 2$ & di-BBPA & 1.475 & 386 \\
\hline D & mono-BBPA & 1.634 & 307 \\
\hline
\end{tabular}

substitution, and dihydroxylation. However, according to an extensive literature survey there were not many studies on discussion of graphene derivatives with $\mathrm{ZnO}$ or $\mathrm{TiO}_{2}$ nanocomposite photodegradation by using GC-MS or EIS-MS. Few studies of $\mathrm{ZnO}$ or $\mathrm{TiO}_{2}$ were characterized by GC-MS or EIS-MS.

\section{PRESENT CHALLENGES AND FUTURE PERSPECTIVES}

To date, a wide variety of nanocomposites from graphene and its derivative with metal oxides are being developed for use in photocatalysis field. The research in this area is still ongoing and continually expanding as they have to overcome the technological and economic barriers in order to be practically viable. There are several concerns about the existing systems that must be addressed. Firstly, there are presently no ways of producing graphene derivatives in huge amounts which are scalable and affordable despite their remarkable applicability. Secondly, researchers have demonstrated that the photocatalytic performance of these graphene-based nanocomposites could be increase by enhancing the absorption of light, load separation and conveyance, and a longer operational life of the nanocomposite systems. Based on this point of view, some constrain need to be focused on to overcome the major scientific and technical problems preventing their utilization in applications at large scale and make it unsuitable at economic importance. For example the synthesis and design of the new graphene-based nanocomposites for photocatalyst still require integral thinking; hence the success of photocatalysis will demand future interdisciplinary effort between researchers and engineers. This approach might be useful in addressing the post-revival, recyclability, and reusability of nanocomposites. Next is the stability in the development of photocatalysts is another significant problem due to their limited useful lives and photocorrosion. For example, $\mathrm{ZnO}$ or $\mathrm{TiO}_{2}$-based photocatalysts, photocorrosion is more critical than chemical corrosion. To date, numerous researches have concentrated on the improvement of $\mathrm{ZnO}$ or $\mathrm{TiO}_{2}$-based photocatalyst photocorrosion resistance and this should be extended to other system too. Further, bioinspiration can be a suitable technique to build new, effective, light-trapped, pollutantabsorbing designs. The synthesis of GO from waste material is an ideal approach to overcome the synthesis problem.

\section{CONCLUSION}

In summary, graphene/ $\mathrm{ZnO}$ and graphene/ $\mathrm{TiO}_{2}$ nanocomposites were studied in the expansion of new and futuristic photocatalysis materials. The present review highlighted the literature survey about graphene/ZnO and graphene/ $\mathrm{TiO}_{2}$ nanocomposites from 2010 to 2020 . The coupling between graphene and photoactive metal oxide semiconductors increases the photocatalytic function of metal oxide for the destruction of different aquatic contaminants such as organic dyes, heavy metal ions and pathogens. Graphene's unique features in conjunction with nanomaterials' size-dependent features provide other capabilities such as high adsorption capacity, wider light absorption range and better charging separation capabilities and great stability. The development of graphene/ metal oxide nanocomposite-based water treatment technology is a very intriguing but tough challenge for researchers since there still are few issues, such as what the future of these composites will be like, and how environmentally friendly do they become? This also represents an important problem for the recycling and disposal of these expired composites. Strategies for the recycling and disposal in home water purity devices for waste creation will be developed concurrently. Finally, the conclusion is, the graphene/metal oxide nanocomposite has enormous possibilities as an effective photocatalyst, the problems with these materials need to be solved, for example with the nature of the chemical interaction or the bonding of metal oxides and the graphene. The need to study them carefully in order to make a more efficient photocatalyst is not fully known. In order to maximize output from these composites, thorough research on the optimization of the graphene content in the composite is needed.

\section{AUTHOR CONTRIBUTIONS}

$\mathrm{KU}$ and $\mathrm{HJ}$ : Conceptualization, writing-original draft preparation, visualization, investigation. RA, MR, MM: Reviewing and Editing, This article has been read and approved by all listed authors.

\section{FUNDING}

This research was funded by Universiti Sains Malaysia, 11800, Pulau Pinang, Malaysia. 


\section{REFERENCES}

Ahmad, A., Hamidah Mohd Setapar, S., Ali Yaqoob, A., and Nasir Mohamad Ibrahim, M. (2021). Synthesis and Characterization of GO-Ag Nanocomposite for Removal of Malachite Dye from Aqueous Solution. Mater. Today Proc. doi:10.1016/j.matpr.2021.03.643

Ahmad, A., Lokhat, D., and Rafatullah, M. (2019). Survey of Graphene-Based Nanotechnologies. In Graphene-Based Nanotechnologies for Energy and Environment. Elsevier, 23-39. doi:10.1016/b978-0-12-815811-1.00002-8

Ahmad, M., Ahmed, E., Hong, Z. L., Khalid, N. R., Ahmed, W., and Elhissi, A. (2013). Graphene-Ag/ZnO Nanocomposites as High Performance Photocatalysts under Visible Light Irradiation. J. Alloys Comp. 577, 717-727. doi:10.1016/j.jallcom.2013.06.137

Ahmed, S. N., and Haider, W. (2021). Enhanced Photocatalytic Activity of ZnOGraphene Oxide Nanocomposite by Electron Scavenging. Catalysts 11 (2), 187. doi: $10.3390 /$ catal11020187

Ahmed, S. N., and Haider, W. (2018). Heterogeneous Photocatalysis and its Potential Applications in Water and Wastewater Treatment: A Review. Nanotechnology 29, 342001. doi:10.1088/1361-6528/aac6ea

Alamelu, K., and Jaffar Ali, B. M. (2020). Au Nanoparticles Decorated Sulfonated Graphene-TiO2 Nanocomposite for Sunlight Driven Photocatalytic Degradation of Recalcitrant Compound. Solar Energy 211, 1194-1205. doi:10.1016/j.solener.2020.10.058

Alkaim, A. F., Aljeboree, A. M., Alrazaq, N. A., Baqir, S. J., Hussein, F. H., and Lilo, A. J. (2014). Effect of $\mathrm{pH}$ on Adsorption and Photocatalytic Degradation Efficiency of Different Catalysts on Removal of Methylene Blue. Asian J. Chem. 26 (24), 8445-8448. doi:10.14233/ajchem.2014.17908

Alves, Z., Nunes, C., and Ferreira, P. (2021). Unravelling the Role of Synthesis Conditions on the Structure of Zinc Oxide-Reduced Graphene Oxide Nanofillers. Nanomaterials 11, 2149. doi:10.3390/nano11082149

Aslam, M., Abdullah, A. Z., and Rafatullah, M. (2021). Recent Development in the green Synthesis of Titanium Dioxide Nanoparticles Using Plant-Based Biomolecules for Environmental and Antimicrobial Applications. J. Ind. Eng. Chem. 98, 1-16. doi:10.1016/j.jiec.2021.04.010

Assi, N., Mohammadi, A., Sadr Manuchehri, Q., and Walker, R. B. (2015). Synthesis and Characterization of $\mathrm{ZnO}$ Nanoparticle Synthesized by a Microwave-Assisted Combustion Method and Catalytic Activity for the Removal of Ortho-Nitrophenol. Desalination Water Treat. 54, 1939-1948. doi:10.1080/19443994.2014.891083

Assmann, C., Scott, A., and Biller, D. (2017). Online Total Organic Carbon (TOC) Monitoring for Water and Wastewater Treatment Plants Processes and Operations Optimization. Drink. Water Eng. Sci. 10, 61-68. doi:10.5194/ dwes-10-61-2017

Atchudan, R., Edison, T. N. J. I., Perumal, S., Karthikeyan, D., and Lee, Y. R. (2016). Facile Synthesis of Zinc Oxide Nanoparticles Decorated Graphene Oxide Composite via Simple Solvothermal Route and Their Photocatalytic Activity on Methylene Blue Degradation. J. Photochem. Photobiol. B: Biol. 162, 500-510. doi:10.1016/j.jphotobiol.2016.07.019

Atchudan, R., Edison, T. N. J. I., Perumal, S., Shanmugam, M., and Lee, Y. R. (2017). Direct Solvothermal Synthesis of Zinc Oxide Nanoparticle Decorated Graphene Oxide Nanocomposite for Efficient Photodegradation of Azo-Dyes. J. Photochem. Photobiol. A: Chem. 337, 100-111. doi:10.1016/ j.jphotochem.2017.01.021

Azarang, M., Shuhaimi, A., Yousefi, R., and Sookhakian, M. (2014). Effects of Graphene Oxide Concentration on Optical Properties of $\mathrm{ZnO} / \mathrm{RGO}$ Nanocomposites and Their Application to Photocurrent Generation. J. Appl. Phys. 116, 084307. doi:10.1063/1.4894141

Baldissarelli, V. Z., De Souza, T., Andrade, L., Oliveira, L. F. C. d., José, H. J., and Moreira, R. D. F. P. M. (2015). Preparation and Photocatalytic Activity of TiO2Exfoliated Graphite Oxide Composite Using an Ecofriendly Graphite Oxidation Method. Appl. Surf. Sci. 359, 868-874. doi:10.1016/j.apsusc.2015.10.199

Basnet, P., Samanta, D., Chanu, T. I., and Chatterjee, S. (2021). Visible Light Facilitated Degradation of Alternate Dye Solutions by Highly Reusable MnZnO Nano-Photocatalyst. J. Alloys Comp. 867, 158870. doi:10.1016/ j.jallcom.2021.158870

Bhanvase, B. A., Shende, T. P., and Sonawane, S. H. (2017). A Review on Graphene$\mathrm{TiO} 2$ and Doped Graphene-TiO2 Nanocomposite Photocatalyst for Water and
Wastewater Treatment. Environ. Tech. Rev. 6, 1-14. doi:10.1080/ 21622515.2016.1264489

Biris, A. R., Toloman, D., Popa, A., Lazar, M. D., Kannarpady, G. K., Saini, V., et al. (2016). Synthesis of Tunable Core-Shell Nanostructures Based on TiO2Graphene Architectures and Their Application in the Photodegradation of Rhodamine Dyes. Physica E: Low-Dimensional Syst. Nanostructures 81, 326-333. doi:10.1016/j.physe.2016.03.028

Bizani, E., Fytianos, K., Poulios, I., and Tsiridis, V. (2006). Photocatalytic Decolorization and Degradation of Dye Solutions and Wastewaters in the Presence of Titanium Dioxide. J. Hazard. Mater. 136, 85-94. doi:10.1016/ j.jhazmat.2005.11.017

Botsa, S. M., Naidu, G. P., Ravichandra, M., Rani, S. J., Anjaneyulu, R. B., and Ramana, C. V. (2020). Flower like SnO2-Fe2O3-rGO Ternary Composite as Highly Efficient Visible Light Induced Photocatalyst for the Degradation of Organic Pollutants from Contaminated Water. J. Mater. Res. Tech. 9 (6), 12461-12472. doi:10.1016/j.jmrt.2020.08.087

Cao, M., Wang, P., Ao, Y., Wang, C., Hou, J., and Qian, J. (2015). Photocatalytic Degradation of Tetrabromobisphenol A by a Magnetically Separable GrapheneTiO2 Composite Photocatalyst: Mechanism and Intermediates Analysis. Chem. Eng. J. 264, 113-124. doi:10.1016/j.cej.2014.10.011

Chang, H., Sun, Z., Ho, K. Y.-F., Tao, X., Yan, F., Kwok, W.-M., et al. (2011). A Highly Sensitive Ultraviolet Sensor Based on a Facile In Situ Solution-Grown ZnO Nanorod/graphene Heterostructure. Nanoscale 3, 258-264. doi:10.1039/ c0nr00588f

Chauhan, P. S., Kant, R., Rai, A., Gupta, A., and Bhattacharya, S. (2019). Facile Synthesis of $\mathrm{ZnO} / \mathrm{GO}$ Nanoflowers over Si Substrate for Improved Photocatalytic Decolorization of MB Dye and Industrial Wastewater under Solar Irradiation. Mater. Sci. Semiconductor Process. 89, 6-17. doi:10.1016/j.mssp.2018.08.022

Chen, J., Li, Y., Huang, L., Li, C., and Shi, G. (2015). High-yield Preparation of Graphene Oxide from Small Graphite Flakes via an Improved Hummers Method with a Simple Purification Process. Carbon 81, 826-834. doi:10.1016/j.carbon.2014.10.033

Chen, Y., Dong, X., Cao, Y., Xiang, J., and Gao, H. (2017). Enhanced Photocatalytic Activities of Low-Bandgap TiO2-Reduced Graphene Oxide Nanocomposites. J. Nanopart Res. 19, 1-13. doi:10.1007/s11051-017-3871-1

Cho, K. M., Kim, K. H., Choi, H. O., and Jung, H.-T. (2015). A Highly Photoactive, Visible-Light-Driven graphene/2D Mesoporous TiO2 Photocatalyst. Green. Chem. 17, 3972-3978. doi:10.1039/c5gc00641d

Choudhari, A., Bhanvase, B. A., Saharan, V. K., Salame, P. H., and Hunge, Y. (2020). Sonochemical Preparation and Characterization of $\mathrm{rGO} / \mathrm{SnO} 2$ Nanocomposite: Electrochemical and Gas Sensing Performance. Ceramics Int. 46 (8), 11290-11296. doi:10.1016/j.ceramint.2020.01.156

Delekar, S. D., Dhodamani, A. G., More, K. V., Dongale, T. D., Kamat, R. K., Acquah, S. F. A., et al. (2018). Structural and Optical Properties of Nanocrystalline TiO2 with Multiwalled Carbon Nanotubes and its Photovoltaic Studies Using Ru(II) Sensitizers. ACS Omega 3 (3), 2743-2756. doi:10.1021/acsomega.7b01316

Depuccio, D. P., Botella, P., O’Rourke, B., and Landry, C. C. (2015). Degradation of Methylene Blue Using Porous WO3, SiO2-WO3, and Their Au-Loaded Analogs: Adsorption and Photocatalytic Studies. ACS Appl. Mater. Inter. 7, 1987-1996. doi:10.1021/am507806a

Dhodamani, A. G., More, K. V., Koli, V. B., Shelke, A. R., Deshpande, N. G., Panda, D. K., et al. (2019). Compositional Dependent Physicochemical and Photovoltaic Properties of the (TiO2)1-x (RGO)x Nanocomposites for Sensitized Solar Cells Using Ru(II) Dyes. ChemistrySelect 4 (3), 1055-1068. doi:10.1002/slct.201803495

Dhodamani, A. G., More, K. V., Mullani, S. B., Deshmukh, S. P., Koli, V. B., Panda, D. K., et al. (2020). Structural Refinement and Optoelectronic Properties of (Mo X Ti 1-2x O 2- $\delta$ ) 1-y (RGO) Y Nanocomposites and Their Photovoltaic Studies with Natural Pigments as Sensitizers. ChemistrySelect 5 (1), 218-230. doi:10.1002/slct.201903606

Dhodamani, A. G., More, K. V., Patil, S. M., Shelke, A. R., Shinde, S. K., Kim, D. Y., et al. (2020). Synergistics of $\mathrm{Cr}(\mathrm{III})$ Doping in TiO2/MWCNTs Nanocomposites: Their Enhanced Physicochemical Properties in Relation to Photovoltaic Studies. Solar Energy 201, 398-408. doi:10.1016/j.solener.2020.03.001

Divya, K. S., Madhu, A. K., Umadevi, T. U., Suprabha, T., Nair, P. R., and Suresh, M. (2017). Improving the Photocatalytic Performance of TiO2 via Hybridizing with Graphene. J. Semicond. 38, 063002. doi:10.1088/1674-4926/38/6/063002 
Du, X., Wang, S., Liu, Y., Lu, M., Wu, K., and Lu, M. (2019). Self-assembly of FreeStanding Hybrid Film Based on Graphene and Zinc Oxide Nanoflakes for HighPerformance Supercapacitors. J. Solid State. Chem. 277, 441-447. doi:10.1016/ j.jssc.2019.06.003

Duan, J., Liu, M., Guo, Y., Wang, W., Zhang, Z., and Li, C. (2020). High Photocatalytic Activity of 2D Sheet Structure ZnO/Bi2WO6 Z-Scheme Heterojunction under Simulated Sunlight. J. Phys. D: Appl. Phys. 53, 165101. doi:10.1088/1361-6463/ab6df9

Escherichia, P., Koli, V. B., Ke, S., Dodamani, A. G., and Deshmukh, S. P. (2020). Boron-doped TiO2-CNT Nanocomposites with Improved Photocatalytic Efficiency toward Photodegradation of Toluene Gas and Photo-Inactivation of Escherichia coli. Catalysts 10, 632.

Feng, Y., Feng, N., Wei, Y., and Zhang, G. (2014). An In Situ Gelatin-Assisted Hydrothermal Synthesis of ZnO-Reduced Graphene Oxide Composites with Enhanced Photocatalytic Performance under Ultraviolet and Visible Light. RSC Adv. 4, 7933-7943. doi:10.1039/c3ra46417b

Frindy, S., and Sillanpää, M. (2020). Synthesis and Application of Novel $\alpha-\mathrm{Fe} 2 \mathrm{O} 3 /$ graphene for Visible-Light Enhanced Photocatalytic Degradation of RhB. Mater. Des. 188, 108461. doi:10.1016/j.matdes.2019.108461

Gao, W. (2012). Graphite Oxide: Structure, Reduction and Applications. Texas United States: Rice University.

Gebreslassie, T. W., Pattabi, M., and Pattabi, R. M. (2013). Review on the Photocatalytic Degradation of Dyes and Antibacterial Activities of Pure and Doped-ZnO. Int. J. Sci. Res. 4, 2252-2264.

Giovannetti, R., Rommozzi, E., Zannotti, M., and D'Amato, C. A. (2017). Recent Advances in Graphene Based TiO2 Nanocomposites (GTiO2Ns) for Photocatalytic Degradation of Synthetic Dyes. Catalysts 7, 305. doi:10.3390/ catal7100305

Gnaser, H., Savina, M. R., Calaway, W. F., Tripa, C. E., Veryovkin, I. V., and Pellin, M. J. (2005). Photocatalytic Degradation of Methylene Blue on Nanocrystalline TiO2: Surface Mass Spectrometry of Reaction Intermediates. Int. J. Mass Spectrom. 245, 61-67. doi:10.1016/j.ijms.2005.07.003

Govindaraj, T., Mahendran, C., Manikandan, V. S., Archana, J., Shkir, M., and Chandrasekaran, J. (2021). Fabrication of WO3 Nanorods/RGO Hybrid Nanostructures for Enhanced Visible-Light-Driven Photocatalytic Degradation of Ciprofloxacin and Rhodamine B in an Ecosystem. J. Alloys Comp. 868, 159091. doi:10.1016/j.jallcom.2021.159091

Gupta, B. K., Kedawat, G., Agrawal, Y., Kumar, P., Dwivedi, J., and Dhawan, S. K. (2015). A Novel Strategy to Enhance Ultraviolet Light Driven Photocatalysis from Graphene Quantum Dots Infilled TiO2 Nanotube Arrays. RSC Adv. 5, 10623-10631. doi:10.1039/c4ra14039g

Han, W., Ren, L., Zhang, Z., Qi, X., Liu, Y., Huang, Z., et al. (2015). Graphenesupported Flocculent-like $\mathrm{TiO} 2$ Nanostructures for Enhanced Photoelectrochemical Activity and Photodegradation Performance. Ceramics Int. 41, 7471-7477. doi:10.1016/j.ceramint.2015.02.068

Haseen, U., Umar, K., Ahmad, H., Parveen, T., and Mohamad Ibrahim, M. N. (2020). Graphene and its Composites: Applications in Environmental Remediation. In Modern Age Waste Water Problems. Springer, 85-91. doi:10.1007/978-3-030-08283-3_5

Hayati, F., Isari, A. A., Fattahi, M., Anvaripour, B., and Jorfi, S. (2018). Photocatalytic Decontamination of Phenol and Petrochemical Wastewater through $\mathrm{ZnO} / \mathrm{TiO} 2$ Decorated on Reduced Graphene Oxide Nanocomposite: Influential Operating Factors, Mechanism, and Electrical Energy Consumption. RSC Adv. 8, 40035-40053. doi:10.1039/c8ra07936f

Horikoshi, S., Tokunaga, A., Hidaka, H., and Serpone, N. (2004). Environmental Remediation by an Integrated Microwave/UV Illumination Method. J. Photochem. Photobiol. A: Chem. 162, 33-40. doi:10.1016/S1010-6030(03) $00312-5$

Hu, X., Mohamood, T., Ma, W., Chen, C., and Zhao, J. (2006). Oxidative Decomposition of Rhodamine B Dye in the Presence of VO2+and/or Pt(IV) under Visible Light Irradiation: N-Deethylation,Chromophore Cleavage, and Mineralization. J. Phys. Chem. B 110, 26012-26018. doi:10.1021/jp063588q

$\mathrm{Hu}, \mathrm{X}$., Xu, P., Gong, H., and Yin, G. (2018). Synthesis and Characterization of WO3/graphene Nanocomposites for Enhanced Photocatalytic Activities by One-step In-Situ Hydrothermal Reaction. Materials 11, 147. doi:10.3390/ ma11010147

Hunge, Y. M., Yadav, A. A., Dhodamani, A. G., Suzuki, N., Terashima, C., Fujishima, A., et al. (2020). Enhanced Photocatalytic Performance of
Ultrasound Treated GO/TiO2 Composite for Photocatalytic Degradation of Salicylic Acid under Sunlight Illumination. Ultrason. Sonochem. 61, 104849. doi:10.1016/j.ultsonch.2019.104849

Hunge, Y. M., Yadav, A. A., Khan, S., Takagi, K., Suzuki, N., Teshima, K., et al. (2021). Photocatalytic Degradation of Bisphenol A Using Titanium Dioxide@ nanodiamond Composites under UV Light Illumination. J. Colloid Interf. Sci. 582, 1058-1066. doi:10.1016/j.jcis.2020.08.102

Hussain, I., Hussain, A., Ahmad, A., Rahman, H., Alajmi, M. F., Ahmed, F., et al. (2019). New Generation Graphene Oxide for Removal of Polycyclic Aromatic Hydrocarbons. In Graphene-Based Nanotechnologies for Energy and Environment. Elsevier, 241-266. doi:10.1016/b978-0-12815811-1.00014-4

Jabeen, M., Ishaq, M., Song, W., Xu, L., Maqsood, I., and Deng, Q. (2017). UVassisted Photocatalytic Synthesis of ZnO-Reduced Graphene Oxide Nanocomposites with Enhanced Photocatalytic Performance in Degradation of Methylene Blue. ECS J. Solid State. Sci. Technol. 6, M36-M43. doi:10.1149/ 2.0231704 jss

Jana, A., and Gregory, D. H. (2020). Microwave-Assisted Synthesis of ZnO-rGO Core-Shell Nanorod Hybrids with Photo- and Electro-Catalytic Activity. Chem. Eur. J. 26 (29), 6703-6714. doi:10.1002/chem.202000535

Jawaid, M., Ahmad, A., and Lokhat, D. (2019). Graphene-Based Nanotechnologies for Energy and Environmental Applications. In Micro and Nano Technologies. Elsevier. doi:10.1595/205651320x15904919310284

Justh, N., Berke, B., László, K., Bakos, L. P., Szabó, A., Hernádi, K., et al. (2018). Preparation of Graphene Oxide/semiconductor Oxide Composites by Using Atomic Layer Deposition. Appl. Surf. Sci. 453, 245-251. doi:10.1016/ j.apsusc.2018.05.064

Khan, M. Y., Ahmad, M., Sadaf, S., Iqbal, S., Nawaz, F., and Iqbal, J. (2019). Visible Light Active Indigo dye/graphene/WO3 Nanocomposites with Excellent Photocatalytic Activity. J. Mater. Res. Tech. 8 (3), 3261-3269. doi:10.1016/ j.jmrt.2019.05.015

Kim, J., Kim, D., Lee, W., Lee, Y., and Kim, H. (2017). Impact of Total Organic Carbon and Specific Surface Area on the Adsorption Capacity in Horn River Shale. J. Pet. Sci. Eng. 149, 331-339. doi:10.1016/j.petrol.2016.10.053

Kim, T.-W., Park, M., Kim, H. Y., and Park, S.-J. (2016). Preparation of Flower-like $\mathrm{TiO} 2$ Sphere/reduced Graphene Oxide Composites for Photocatalytic Degradation of Organic Pollutants. J. Solid State. Chem. 239, 91-98. doi:10.1016/j.jssc.2016.04.010

Kim, T., Parale, V., Jung, H.-N. -R., Kim, Y., Driss, Z., Driss, D., et al. (2019). Facile Synthesis of SnO2 Aerogel/Reduced Graphene Oxide Nanocomposites via In Situ Annealing for the Photocatalytic Degradation of Methyl Orange. Nanomaterials 9 (3), 358. doi:10.3390/nano9030358

Kodarkar, N. M., Deosarkar, M. P., and Bhanvase, B. A. (2021). Ultrasound Assisted One Step In-Situ Preparation and Characterization of rGO-WO3 Nanocomposite for Degradation of Organic Dyes. Chem. Eng. Process. - Process Intensification 163, 108367. doi:10.1016/j.cep.2021.108367

Koli, V., Dhodamani, A., More, K., Acquah, S. F. A., Panda, D. K., Pawar, S., et al. (2017). A Simple Strategy for the Anchoring of Anatase Titania on MultiWalled Carbon Nanotubes for Solar Energy Harvesting. Solar Energy 149, 188-194. doi:10.1016/j.solener.2017.03.036

Kumar, A., Sharma, G., Naushad, M., Al-Muhtaseb, A. a. H., García-Peñas, A., Mola, G. T., et al. (2020). Bio-inspired and Biomaterials-Based Hybrid Photocatalysts for Environmental Detoxification: A Review. Chem. Eng. J. 382, 122937. doi:10.1016/j.cej.2019.122937

Kumar, S., Pandit, V., Bhattacharyya, K., and Krishnan, V. (2018). Sunlight Driven Photocatalytic Reduction of 4-nitrophenol on Pt Decorated ZnO-RGO Nanoheterostructures. Mater. Chem. Phys. 214, 364-376. doi:10.1016/ j.matchemphys.2018.04.113

La, D. D., Bhosale, S. V., Jones, L. A., Revaprasadu, N., and Bhosale, S. V. (2017). Fabrication of a Graphene@TiO 2 @Porphyrin Hybrid Material and its Photocatalytic Properties under Simulated Sunlight Irradiation. ChemistrySelect 2, 3329-3333. doi:10.1002/slct.201700473

Lai, Y., Meng, M., and Yu, Y. (2010). One-step Synthesis, Characterizations and Mechanistic Study of Nanosheets-Constructed Fluffy $\mathrm{ZnO}$ and $\mathrm{Ag} / \mathrm{ZnO}$ Spheres Used for Rhodamine B Photodegradation. Appl. Catal. B: Environ. 100, 491-501. doi:10.1016/j.apcatb.2010.08.027

Lavanya, T., Dutta, M., Ramaprabhu, S., and Satheesh, K. (2017). Superior Photocatalytic Performance of Graphene Wrapped Anatase/rutile Mixed 
Phase TiO2 Nanofibers Synthesized by a Simple and Facile Route. J. Environ. Chem. Eng. 5, 494-503. doi:10.1016/j.jece.2016.12.025

Lee, K. M., Lai, C. W., Ngai, K. S., and Juan, J. C. (2016). Recent Developments of Zinc Oxide Based Photocatalyst in Water Treatment Technology: A Review. Water Res. 88, 428-448. doi:10.1016/j.watres.2015.09.045

Li, B., and Cao, H. (2011). ZnO@graphene Composite with Enhanced Performance for the Removal of Dye from Water. J. Mater. Chem. 21, 3346-3349. doi:10.1039/c0jm03253k

Liang, Y., Wang, H., Sanchez Casalongue, H., Chen, Z., and Dai, H. (2010). TiO2 Nanocrystals Grown on Graphene as Advanced Photocatalytic Hybrid Materials. Nano Res. 3, 701-705. doi:10.1007/s12274-010-0033-5

Liu, H., Wang, Y., Shi, L., Xu, R., Huang, L., and Tan, S. (2016). Utilization of Reduced Graphene Oxide for the Enhancement of Photocatalytic Property of TiO2nanotube. Desalination Water Treat. 57, 13263-13272. doi:10.1080/ 19443994.2015.1060172

Liu, J., Wang, Y., Jiang, B., Wang, L., Chen, J., Guo, H., et al. (2013). Degradation, Metabolism, and Bound-Residue Formation and Release of Tetrabromobisphenol A in Soil during Sequential Anoxic-Oxic Incubation. Environ. Sci. Technol. 47, 8348-8354. doi:10.1021/es4014322

Liu, W. M., Li, J., and Zhang, H. Y. (2020). Reduced Graphene Oxide Modified Zinc Oxide Composites Synergistic Photocatalytic Activity under Visible Light Irradiation. Optik 207, 163778. doi:10.1016/j.ijleo.2019.163778

Liu, Y., Hu, Y., Zhou, M., Qian, H., and Hu, X. (2012). Microwave-assisted Nonaqueous Route to deposit Well-Dispersed $\mathrm{ZnO}$ Nanocrystals on Reduced Graphene Oxide Sheets with Improved Photoactivity for the Decolorization of Dyes under Visible Light. Appl. Catal. B: Environ. 125, 425-431. doi:10.1016/ j.apcatb.2012.06.016

Lonkar, S. P., Pillai, V., and Abdala, A. (2019). Solvent-free Synthesis of ZnOGraphene Nanocomposite with superior Photocatalytic Activity. Appl. Surf. Sci. 465, 1107-1113. doi:10.1016/j.apsusc.2018.09.264

Lum, P. T., Foo, K. Y., Zakaria, N. A., and Palaniandy, P. (2020). Ash Based Nanocomposites for Photocatalytic Degradation of Textile Dye Pollutants: A Review. Mater. Chem. Phys. 241, 122405. doi:10.1016/ j.matchemphys.2019.122405

Luo, S., Yang, S., Wang, X., and Sun, C. (2010). Reductive Degradation of Tetrabromobisphenol A over Iron-Silver Bimetallic Nanoparticles under Ultrasound Radiation. Chemosphere 79, 672-678. doi:10.1016/ j.chemosphere.2010.02.011

Malik, A., Hameed, S., Siddiqui, M. J., Haque, M. M., Umar, K., Khan, A., et al. (2014). Electrical and Optical Properties of Nickel- and Molybdenum-Doped Titanium Dioxide Nanoparticle: Improved Performance in Dye-Sensitized Solar Cells. J. Materi Eng. Perform. 23 (9), 3184-3192. doi:10.1007/s11665014-0954-3

Mandal, B., Panda, J., and Tudu, B. (2018). Synthesis and Characterization of Nanocomposite GO@ $\alpha-F e 2 \mathrm{O}$ :Efficient Material for Dye Removal. AIP Conf. Proc. 1953, 030173. doi:10.1063/1.5032508

Marlinda, A. R., Huang, N. M., Muhamad, M. R., An'amt, M. N., Chang, B. Y. S., Yusoff, N., et al. (2012). Highly Efficient Preparation of $\mathrm{ZnO}$ Nanorods Decorated Reduced Graphene Oxide Nanocomposites. Mater. Lett., 80, 9-12. doi:10.1016/j.matlet.2012.04.061

Min, Y., He, G., Li, R., Zhao, W., Chen, Y., and Zhang, Y. (2013). Doping Nitrogen Anion Enhanced Photocatalytic Activity on TiO2 Hybridized with Graphene Composite under Solar Light. Sep. Purif. Tech. 106, 97-104. doi:10.1016/ j.seppur.2012.12.023

Mir, N. A., Haque, M. M., Khan, A., Umar, K., Muneer, M., and Vijayalakshmi, S. (2012). Semiconductor Mediated Photocatalysed Reaction of Two Selected Organic Compounds in Aqueous Suspensions of Titanium Dioxide. J. Adv. Oxidation Tech. 15 (2), 380-391. doi:10.1515/jaots-2012-0218

Mir, N., Khan, A., Umar, K., and Muneer., M. (2013). Photocatalytic Study of a Xanthene Dye Derivative, Phloxine B in Aqueous Suspension of TiO2: Adsorption Isotherm and Decolourization Kinetics. Energy Environ. Focus 2 (3), 208-216. doi:10.1166/eef.2013.1052

Mirikaram, N., Pérez-Molina, Á., Morales-Torres, S., Salemi, A., MaldonadoHódar, F. J., and Pastrana-Martínez, L. M. (2021). Photocatalytic Perfomance of $\mathrm{ZnO}$-Graphene Oxide Composites towards the Degradation of Vanillic Acid under Solar Radiation and Visible-LED. Nanomaterials 11, 1576. doi:10.3390/nano1 1061576
Mohamed, M. M., Ghanem, M. A., Khairy, M., Naguib, E., and Alotaibi, N. H. (2019). Zinc Oxide Incorporated Carbon Nanotubes or Graphene Oxide Nanohybrids for Enhanced Sonophotocatalytic Degradation of Methylene Blue Dye. Appl. Surf. Sci. 487, 539-549. doi:10.1016/j.apsusc.2019.05.135

Mohd Adnan, M. A., Phoon, B. L., and Muhd Julkapli, N. (2020). Mitigation of Pollutants by Chitosan/metallic Oxide Photocatalyst: A Review. J. Clean. Prod. 261, 121190. doi:10.1016/j.jclepro.2020.121190

Molla, A., Sahu, M., and Hussain, S. (2015). Under Dark and Visible Light: Fast Degradation of Methylene Blue in the Presence of Ag-In-Ni-S Nanocomposites. J. Mater. Chem. A. 3, 15616-15625. doi:10.1039/c5ta02888d

Moma, J., and Baloyi, J. (2019). "Modified Titanium Dioxide for Photocatalytic Applications," in Photocatalysts - Applications and Attributes. Editors S. B. Khan and K. Akhtar. doi:10.5772/intechopen.79374

Mullani, S. B., Dhodamani, A. G., Shellikeri, A., Mullani, N. B., Tawade, A. K., Tayade, S. N., et al. (2020). Structural Refinement and Electrochemical Properties of One Dimensional ( $\mathrm{ZnO}$ NRs) $1-\mathrm{x}(\mathrm{CNs}) \mathrm{x}$ Functional Hybrids for Serotonin Sensing Studies. Sci. Rep. 10, 15955. doi:10.1038/s41598-02072756-3

Nabi, G., Ain, Q.-U., Tahir, M. B., Nadeem Riaz, K., Iqbal, T., Rafique, M., et al. (2020). Green Synthesis of TiO2 Nanoparticles Using Lemon Peel Extract: Their Optical and Photocatalytic Properties. Int. J. Environ. Anal. Chem. 1, 1-9. doi:10.1080/03067319.2020.1722816

Nenavathu, B. P., Kandula, S., and Verma, S. (2018). Visible-light-driven Photocatalytic Degradation of Safranin-T Dye Using Functionalized Graphene Oxide Nanosheet (FGS)/ZnO Nanocomposites. RSC Adv. 8, 19659-19667. doi:10.1039/c8ra02237b

$\mathrm{Ng}, \mathrm{K} . \mathrm{H}$., and Cheng, C. K. (2016). Photo-polishing of POME into CH4-Lean Biogas over the UV-Responsive ZnO Photocatalyst. Chem. Eng. J. 300, 127-138. doi:10.1016/j.cej.2016.04.105

Nuengmatcha, P., Porrawatkul, P., Chanthai, S., Sricharoen, P., and Limchoowong, N. (2019). Enhanced Photocatalytic Degradation of Methylene Blue Using $\mathrm{Fe} 2 \mathrm{O} 3 /$ graphene/CuO Nanocomposites under Visible Light. J. Environ. Chem. Eng. 7 (6), 103438. doi:10.1016/j.jece.2019.103438

Ortiz Balbuena, J., Tutor De Ureta, P., Rivera Ruiz, E., and Mellor Pita, S. (2016). Enfermedad de Vogt-Koyanagi-Harada. Medicina Clínica 146, 93-94. doi:10.1016/j.medcli.2015.04.005

Pathak, N., Caleb, O. J., Geyer, M., Herppich, W. B., Rauh, C., and Mahajan, P. V. (2017). Photocatalytic and Photochemical Oxidation of Ethylene: Potential for Storage of Fresh Produce-A Review. Food Bioproc. Technol 10, 982-1001. doi:10.1007/s11947-017-1889-0

Posa, V. R., Annavaram, V., Koduru, J. R., Ammireddy, V. R., and Somala, A. R. (2016). Graphene-ZnO Nanocomposite for Highly Efficient Photocatalytic Degradation of Methyl orange Dye under Solar Light Irradiation. Korean J. Chem. Eng. 33, 456-464. doi:10.1007/s11814-015-0145-4

Prabhu, S., Megala, S., Harish, S., Navaneethan, M., Maadeswaran, P., Sohila, S., et al. (2019). Enhanced Photocatalytic Activities of $\mathrm{ZnO}$ Dumbbell/reduced Graphene Oxide Nanocomposites for Degradation of Organic Pollutants via Efficient Charge Separation Pathway. Appl. Surf. Sci. 487, 1279-1288. doi:10.1016/j.apsusc.2019.05.086

Prabhu, S., Pudukudy, M., Sohila, S., Harish, S., Navaneethan, M., Navaneethan, D., et al. (2018). Synthesis, Structural and Optical Properties of ZnO Spindle/ reduced Graphene Oxide Composites with Enhanced Photocatalytic Activity under Visible Light Irradiation. Opt. Mater. 79, 186-195. doi:10.1016/ j.optmat.2018.02.061

Pruna, A., Cembrero, J., Pullini, D., Mocioiu, A. M., and Busquets-Mataix, D. (2017). Effect of Reduced Graphene Oxide on Photocatalytic Properties of Electrodeposited ZnO. Appl. Phys. A. 123, 1-7. doi:10.1007/s00339-017-1424-1

Qi, K., Cheng, B., Yu, J., and Ho, W. (2017). Review on the Improvement of the Photocatalytic and Antibacterial Activities of ZnO. J. Alloys Comp. 727, 792-820. doi:10.1016/j.jallcom.2017.08.142

Qin, J., Zhang, X., Yang, C., Cao, M., Ma, M., and Liu, R. (2017). ZnO Microspheres-Reduced Graphene Oxide Nanocomposite for Photocatalytic Degradation of Methylene Blue Dye. Appl. Surf. Sci. 392, 196-203. doi:10.1016/j.apsusc.2016.09.043

Raizada, P., Kumari, J., Shandilya, P., Dhiman, R., Pratap Singh, V., and Singh, P. (2017). Magnetically Retrievable Bi 2 WO 6/Fe 3 O 4 Immobilized on Graphene Sand Composite for Investigation of Photocatalytic Mineralization of 
Oxytetracycline and Ampicillin. Process Saf. Environ. Prot. 106, 104-116. doi:10.1016/j.psep.2016.12.012

Raizada, P., Sudhaik, A., Singh, P., Shandilya, P., Thakur, P., and Jung, H. (2020). Visible Light Assisted Photodegradation of 2,4-dinitrophenol Using Ag2CO3 Loaded Phosphorus and sulphur Co-doped Graphitic Carbon Nitride Nanosheets in Simulated Wastewater. Arabian J. Chem. 13, 3196-3209. doi:10.1016/j.arabjc.2018.10.004

Rajamanickam, D., and Shanthi, M. (2016). Photocatalytic Degradation of an Organic Pollutant by Zinc Oxide - Solar Process. Arabian J. Chem. 9, S1858-S1868. doi:10.1016/j.arabjc.2012.05.006

Ramachandran, R., Saranya, M., Velmurugan, V., Raghupathy, B. P. C., Jeong, S. K., and Grace, A. N. (2015). Effect of Reducing Agent on Graphene Synthesis and its Influence on Charge Storage towards Supercapacitor Applications. Appl. Energ. 153, 22-31. doi:10.1016/j.apenergy.2015.02.091

Ranjith, K. S., Manivel, P., Rajendrakumar, R. T., and Uyar, T. (2017). Multifunctional $\mathrm{ZnO}$ Nanorod-Reduced Graphene Oxide Hybrids Nanocomposites for Effective Water Remediation: Effective Sunlight Driven Degradation of Organic Dyes and Rapid Heavy Metal Adsorption. Chem. Eng. J. 325, 588-600. doi:10.1016/j.cej.2017.05.105

Rasolevandi, T., Naseri, S., Azarpira, H., and Mahvi, A. H. (2019). Photodegradation of Dexamethasone Phosphate Using UV/Iodide Process: Kinetics, Intermediates, and Transformation Pathways. J. Mol. Liquids 295, 111703. doi:10.1016/j.molliq.2019.111703

Rokhsat, E., and Akhavan, O. (2016). Improving the Photocatalytic Activity of Graphene oxide/ZnO Nanorod Films by UV Irradiation. Appl. Surf. Sci. 371, 590-595. doi:10.1016/j.apsusc.2016.02.222

Ruidíaz-Martínez, M., Álvarez, M. A., López-Ramón, M. V., Cruz-Quesada, G., Rivera-Utrilla, J., and Sánchez-Polo, M. (2020). Hydrothermal Synthesis of RGO-TiO2 Composites as High-Performance UV Photocatalysts for Ethylparaben Degradation. Catalysts 10 (5), 520. doi:10.3390/catal10050520

Safian, M. T.-u., Haron, U. S., and Mohamad Ibrahim, M. N. (2020). A Review on Bio-Based Graphene Derived from Biomass Wastes. BioRes 15, 9756-9785. doi:10.15376/biores.15.4.safian

Sahatiya, P., and Badhulika, S. (2015). One-step In Situ Synthesis of Single Aligned Graphene-ZnO Nanofiber for UV Sensing. RSC Adv. 5, 82481-82487. doi:10.1039/c5ra15351d

Samadi, M., Zirak, M., Naseri, A., Kheirabadi, M., Ebrahimi, M., and Moshfegh, A. Z. (2019). Design and Tailoring of One-Dimensional ZnO Nanomaterials for Photocatalytic Degradation of Organic Dyes: a Review. Res. Chem. Intermed 45, 2197-2254. doi:10.1007/s11164-018-03729-5

Samadi, M., Zirak, M., Naseri, A., Khorashadizade, E., and Moshfegh, A. Z. (2016). Recent Progress on Doped $\mathrm{ZnO}$ Nanostructures for Visible-Light Photocatalysis. Thin Solid Films 605, 2-19. doi:10.1016/j.tsf.2015.12.064

Saravanakumar, B., Mohan, R., and Kim, S.-J. (2013). Facile Synthesis of graphene/ $\mathrm{ZnO}$ Nanocomposites by Low Temperature Hydrothermal Method. Mater. Res. Bull. 48, 878-883. doi:10.1016/j.materresbull.2012.11.048

Serrà, A., Zhang, Y., Sepúlveda, B., Gómez, E., Nogués, J., Michler, J., et al. (2019). Highly Active ZnO-Based Biomimetic Fern-like Microleaves for Photocatalytic Water Decontamination Using Sunlight. Appl. Catal. B: Environ. 248, 129-146. doi:10.1016/j.apcatb.2019.02.017

Shandilya, P., Mittal, D., Soni, M., Raizada, P., Lim, J.-H., Jeong, D. Y., et al. (2018). Islanding of EuVO4 on High-Dispersed Fluorine Doped Few Layered Graphene Sheets for Efficient Photocatalytic Mineralization of Phenolic Compounds and Bacterial Disinfection. J. Taiwan Inst. Chem. Eng. 93, 528-542. doi:10.1016/j.jtice.2018.08.034

Shi, Y., Yu, Z., Li, Z., Zhao, X., and Yuan, Y. (2021). In-Situ Synthesis of TiO2@GO Nanosheets for Polymers Degradation in a Natural Environment. Polymers 13 (13), 2158. doi:10.3390/polym13132158

Shyamala, R., and Gomathi Devi, L. (2020). Reduced Graphene oxide/SnO2 Nanocomposites for the Photocatalytic Degradation of Rhodamine B: Preparation, Characterization, Photosensitization, Vectorial Charge Transfer Mechanism and Identification of Reaction Intermediates. Chem. Phys. Lett. 748, 137385. doi:10.1016/j.cplett.2020.137385

Singh, P., Shandilya, P., Raizada, P., Sudhaik, A., Rahmani-Sani, A., and HosseiniBandegharaei, A. (2020). Review on Various Strategies for Enhancing Photocatalytic Activity of Graphene Based Nanocomposites for Water Purification. Arabian J. Chem. 13, 3498-3520. doi:10.1016/j.arabjc.2018.12.001
Sohail, M., Xue, H., Jiao, Q., Li, H., Khan, K., Wang, S., et al. (2017). Synthesis of Well-Dispersed TiO 2 @reduced Graphene Oxide (rGO) Nanocomposites and Their Photocatalytic Properties. Mater. Res. Bull. 90, 125-130. doi:10.1016/ j.materresbull.2017.02.025

Staudenmaier, L. (1898). Verfahren zur Darstellung der Graphitsäure. Ber. Dtsch. Chem. Ges. 31, 1481-1487. doi:10.1002/cber.18980310237

Suave, J., Amorim, S. M., and Moreira, R. F. P. M. (2017). TiO2-graphene Nanocomposite Supported on Floating Autoclaved Cellular concrete for Photocatalytic Removal of Organic Compounds. J. Environ. Chem. Eng. 5, 3215-3223. doi:10.1016/j.jece.2017.06.028

Sue, H.-J., Li, F., Li, F., Lutkenhaus, J., Kotaki, M., and Yao, H. (2016). Highperformance Photocatalyst Based on Nanosized ZnO-Reduced Graphene Oxide Hybrid for Removal of Rhodamine B under Visible Light Irradiation. AIMS Mater. Sci. 3, 1410-1425. doi:10.3934/ matersci.2016.4.1410

Tobaldi, D. M., Dvoranová, D., Lajaunie, L., Rozman, N., Figueiredo, B., Seabra, M. P., et al. (2021). Graphene-TiO2 Hybrids for Photocatalytic Aided Removal of VOCs and Nitrogen Oxides from Outdoor Environment. Chem. Eng. J. 405, 126651. doi:10.1016/j.cej.2020.126651

Trandafilović, L. V., Jovanović, D. J., Zhang, X., Ptasińska, S., and Dramićanin, M. D. (2017). Enhanced Photocatalytic Degradation of Methylene Blue and Methyl orange by ZnO:Eu Nanoparticles. Appl. Catal. B: Environ. 203, 740-752. doi:10.1016/j.apcatb.2016.10.063

Umar, K., Aris, A., Ahmad, H., Parveen, T., Jaafar, J., Majid, Z. A., et al. (2016). Synthesis of Visible Light Active Doped TiO2 for the Degradation of Organic Pollutants-Methylene Blue and Glyphosate. J. Anal. Sci. Technol. 7, 1-8. doi:10.1186/s40543-016-0109-2

Umar, K., Aris, A., Parveen, T., Jaafar, J., Abdul Majid, Z., Vijaya Bhaskar Reddy, A., et al. (2015). Synthesis, Characterization of Mo and Mn Doped $\mathrm{ZnO}$ and Their Photocatalytic Activity for the Decolorization of Two Different Chromophoric Dyes. Appl. Catal. A: Gen. 505, 507-514. doi:10.1016/ j.apcata.2015.02.001

Umar, K., Dar, A. A., Haque, M. M., Mir, N. A., and Muneer, M. (2012). Photocatalysed Decolourization of Two Textile Dye Derivatives, Martius Yellow and Acid Blue 129, in UV-Irradiated Aqueous Suspensions of Titania. Desalination Water Treat. 46 (1-3), 205-214. doi:10.1080/ 19443994.2012.677527,

Umar, K., Haque, M. M., Mir, N. A., Muneer, \& M., and Farooqi, I. H. (2013). Titanium Dioxide-Mediated Photocatalysed Mineralization of Two Selected Organic Pollutants in Aqueous Suspensions. J. Adv. Oxidation Tech. 16 (2), 252-260. doi:10.1515/jaots-2013-0205

Umar, K., Ibrahim, M. N. M., Ahmad, A., and Rafatullah, M. (2019). Synthesis of Mn-Doped TiO2 by Novel Route and Photocatalytic Mineralization/ intermediate Studies of Organic Pollutants. Res. Chem. Intermed 45, 2927-2945. doi:10.1007/s11164-019-03771-x

Upadhyay, R. K., Soin, N., and Roy, S. S. (2014). Role of Graphene/metal Oxide Composites as Photocatalysts, Adsorbents and Disinfectants in Water Treatment: A Review. RSC Adv. 4, 3823-3851. doi:10.1039/c3ra45013a

Vadivel, S., Paul, B., Maruthamani, D., Kumaravel, M., Vijayaraghavan, T., Hariganesh, S., et al. (2019). Synthesis of Yttrium Doped BiOF/RGO Composite for Visible Light: Photocatalytic Applications. Mater. Sci. Energ. Tech. 2, 112-116. doi:10.1016/j.mset.2018.11.006

Vaiano, V., Matarangolo, M., Murcia, J. J., Rojas, H., Navío, J. A., and Hidalgo, M. C. (2018). Enhanced Photocatalytic Removal of Phenol from Aqueous Solutions Using $\mathrm{ZnO}$ Modified with Ag. Appl. Catal. B: Environ. 225, 197-206. doi:10.1016/j.apcatb.2017.11.075

Van Tuan, P., Phuong, T. T., Tan, V. T., Nguyen, S. X., and Khiem, T. N. (2020). Insitu Hydrothermal Fabrication and Photocatalytic Behavior of $\mathrm{ZnO} /$ reduced Graphene Oxide Nanocomposites with Varying Graphene Oxide Concentrations. Mater. Sci. Semiconductor Process. 115, 105114. doi:10.1016/ j.mssp.2020.105114

Wahab, A. K., Nadeem, M. A., and Idriss, H. (2019). Hydrogen Production during Ethylene Glycol Photoreactions over Ag-Pd/TiO2 at Different Partial Pressures of Oxygen. Front. Chem. 7, 780. doi:10.3389/fchem.2019.00780

Wang, B., Liang, W., Guo, Z., and Liu, W. (2015). Biomimetic Super-lyophobic and Super-lyophilic Materials Applied for Oil/water Separation: A New Strategy beyond Nature. Chem. Soc. Rev. 44, 336-361. doi:10.1039/c4cs00220b 
Wang, N., Zhang, F., Mei, Q., Wu, R., and Wang, W. (2020). Photocatalytic TiO2/ $\mathrm{rGO} / \mathrm{CuO}$ Composite for Wastewater Treatment of $\mathrm{Cr}(\mathrm{VI})$ under Visible Light. Water Air Soil Pollut. 231, 223. doi:10.1007/s11270-020-04609-8

Wang, W., Huang, X., Lai, M., and Lu, C. (2017). RGO/TiO2 Nanosheets Immobilized on Magnetically Actuated Artificial Cilia Film: a New Mode for Efficient Photocatalytic Reaction. RSC Adv. 7, 10517-10523. doi:10.1039/ c6ra26306b

Wang, W., Yu, J., Xiang, Q., and Cheng, B. (2012). Enhanced Photocatalytic Activity of Hierarchical Macro/mesoporous TiO2-Graphene Composites for Photodegradation of Acetone in Air. Appl. Catal. B: Environ. 119-120, 109-116. doi:10.1016/j.apcatb.2012.02.035

Wang, Y., Shi, R., Lin, J., and Zhu, Y. (2010). Significant Photocatalytic Enhancement in Methylene Blue Degradation of $\mathrm{TiO} 2$ Photocatalysts via Graphene-like Carbon In Situ Hybridization. Appl. Catal. B: Environ. 100, 179-183. doi:10.1016/j.apcatb.2010.07.028

Wang, Y., Wang, Q., Zhan, X., Wang, F., Safdar, M., and He, J. (2013). Visible Light Driven Type II Heterostructures and Their Enhanced Photocatalysis Properties: A Review. Nanoscale 5, 8326-8339. doi:10.1039/c3nr01577g

WWAP (2018). United Nations World Water Assessment Programme/UN-Water. Geneva, Switzerland: Unesco.

Xu, C., Zhu, J., Yuan, R., and Fu, X. (2016). More Effective Use of Graphene in Photocatalysis by Conformal Attachment of Small Sheets to TiO2 Spheres. Carbon 96, 394-402. doi:10.1016/j.carbon.2015.09.088

Yadav, A. A., Hunge, Y. M., and Kang, S.-W. (2021). Porous Nanoplate-like Tungsten Trioxide/reduced Graphene Oxide Catalyst for Sonocatalytic Degradation and Photocatalytic Hydrogen Production. Surf. Inter. 24, 101075. doi:10.1016/j.surfin.2021.101075

Yadav, A. A., Kang, S.-W., and Hunge, Y. M. (2021). Photocatalytic Degradation of Rhodamine B Using Graphitic Carbon Nitride Photocatalyst. J. Mater. Sci. Mater. Electron. 32 (11), 15577-15585. doi:10.1007/s10854-021-06106-y

Yadav, R., Kumar, V., Saxena, V., Singh, P., and Singh, V. K. (2019). Preparation of Controlled lotus like Structured $\mathrm{ZnO}$ Decorated Reduced Graphene Oxide Nanocomposites to Obtain Enhanced Photocatalytic Properties. Ceramics Int. 45, 24999-25009. doi:10.1016/j.ceramint.2019.04.142

Yang, C., Dong, W., Cui, G., Zhao, Y., Shi, X., Xia, X., et al. (2017). Highly Efficient Photocatalytic Degradation of Methylene Blue by P2ABSA-Modified TiO2 Nanocomposite Due to the Photosensitization Synergetic Effect of $\mathrm{TiO} 2$ and P2ABSA. RSC Adv. 7, 23699-23708. doi:10.1039/c7ra02423a

Yang, Y., Xu, L., Wang, H., Wang, W., and Zhang, L. (2016). TiO 2/graphene Porous Composite and its Photocatalytic Degradation of Methylene Blue. Mater. Des. 108, 632-639. doi:10.1016/j.matdes.2016.06.104

Yaqoob, A. A., Ibrahim, M. N. M., Ahmad, A., and Vijaya Bhaskar Reddy, A. (2021). Toxicology and Environmental Application of Carbon Nanocomposite. Green. Energ. Tech., 1-18. doi:10.1007/978-981-15-6699-8_1

Yaqoob, A. A., Mohd Noor, N. H. b., Serrà, A., and Mohamad Ibrahim, M. N. (2020). Advances and Challenges in Developing Efficient Graphene OxideBased Zno Photocatalysts for Dye Photo-Oxidation. Nanomaterials 10, 932. doi:10.3390/nano10050932

Yaqoob, A. A., Parveen, T., Umar, K., and Mohamad Ibrahim, M. N. (2020). Role of Nanomaterials in the Treatment of Wastewater: A Review. Water 12, 495. doi:10.3390/w12020495

Yaqoob, A. A., Umar, K., and Ibrahim, M. N. M. (2020). Silver Nanoparticles: Various Methods of Synthesis, Size Affecting Factors and Their Potential Applications-A Review. Appl. Nanosci 10, 1369-1378. doi:10.1007/s13204-020-01318-w

Yin, P., Zhang, L., Wang, J., Feng, X., Wang, K., Rao, H., et al. (2019). Low Frequency Microwave Absorption Property of CIPs/ZnO/Graphene Ternary
Hybrid Prepared via Facile High-Energy ball Milling. Powder Tech. 356, 325-334. doi:10.1016/j.powtec.2019.08.033

Zhang, F., Wang, X., Liu, H., Liu, C., Wan, Y., Long, Y., et al. (2019). Recent Advances and Applications of Semiconductor Photocatalytic Technology. Appl. Sci. 9, 2489. doi:10.3390/app9122489

Zhang, J.-J., Qi, P., Li, J., Zheng, X.-C., Liu, P., Guan, X.-X., et al. (2018). Threedimensional Fe2O3-TiO2-Graphene Aerogel Nanocomposites with Enhanced Adsorption and Visible Light-Driven Photocatalytic Performance in the Removal of RhB Dyes. J. Ind. Eng. Chem. 61, 407-415. doi:10.1016/ j.jiec.2017.12.040

Zhang, N., Li, B., Li, S., and Yang, S. (2017). Graphene-supported Mesoporous Titania Nanosheets for Efficient Photodegradation. J. Colloid Interf. Sci. 505, 711-718. doi:10.1016/j.jcis.2017.06.063

Zhang, X., Wang, Y., Hou, F., Li, H., Yang, Y., Zhang, X., et al. (2017). Effects of Ag Loading on Structural and Photocatalytic Properties of Flower-like $\mathrm{ZnO}$ Microspheres. Appl. Surf. Sci. 391, 476-483. doi:10.1016/ j.apsusc.2016.06.109

Zhang, Y., Hou, X., Sun, T., and Zhao, X. (2017). Calcination of Reduced Graphene Oxide Decorated TiO 2 Composites for Recovery and Reuse in Photocatalytic Applications. Ceramics Int. 43, 1150-1159. doi:10.1016/ j.ceramint.2016.10.056

Zhao, F., Dong, B., Gao, R., Su, G., Liu, W., Shi, L., et al. (2015). A ThreeDimensional Graphene-TiO2 Nanotube Nanocomposite with Exceptional Photocatalytic Activity for Dye Degradation. Appl. Surf. Sci. 351, 303-308. doi:10.1016/j.apsusc.2015.05.121

Zhao, Y., Liu, L., Cui, T., Tong, G., and Wu, W. (2017). Enhanced Photocatalytic Properties of $\mathrm{ZnO} /$ reduced Graphene Oxide Sheets (rGO) Composites with Controllable Morphology and Composition. Appl. Surf. Sci. 412, 58-68. doi:10.1016/j.apsusc.2017.03.207

Zhu, G., Li, X., Wang, H., and Zhang, L. (2017). Microwave Assisted Synthesis of Reduced Graphene Oxide Incorporated MOF-Derived $\mathrm{ZnO}$ Composites for Photocatalytic Application. Catal. Commun. 88, 5-8. doi:10.1016/ j.catcom.2016.09.024

Zouhier, M., Tanji, K., Navio, J. A., Hidalgo, M. C., Jaramillo-Páez, C., and Kherbeche, A. (2020). Preparation of $\mathrm{ZnFe} 2 \mathrm{O} 4 / \mathrm{ZnO}$ Composite: Effect of Operational Parameters for Photocatalytic Degradation of Dyes under UV and Visible Illumination. J. Photochem. Photobiol. A: Chem. 390, 112305. doi:10.1016/j.jphotochem.2019.112305

Conflict of Interest: The authors declare that the research was conducted in the absence of any commercial or financial relationships that could be construed as a potential conflict of interest.

Publisher's Note: All claims expressed in this article are solely those of the authors and do not necessarily represent those of their affiliated organizations, or those of the publisher, the editors and the reviewers. Any product that may be evaluated in this article, or claim that may be made by its manufacturer, is not guaranteed or endorsed by the publisher.

Copyright (c) 2021 Jamjoum, Umar, Adnan, Razali and Mohamad Ibrahim. This is an open-access article distributed under the terms of the Creative Commons Attribution License (CC BY). The use, distribution or reproduction in other forums is permitted, provided the original author(s) and the copyright owner(s) are credited and that the original publication in this journal is cited, in accordance with accepted academic practice. No use, distribution or reproduction is permitted which does not comply with these terms. 